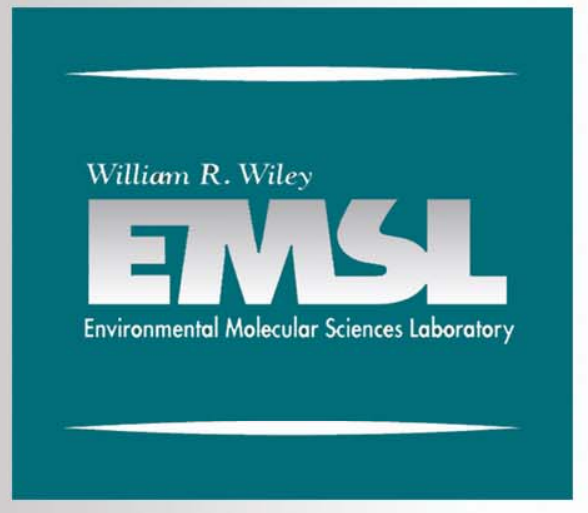

\title{
Computational Studies in Molecular Geochemistry and Biogeochemistry
}
A. R. Felmy
J. R. Rustad
E. J. Bylaska
P. E. Smith
D. A. Dixon
T. P. Straatsma
M. Dupuis
J. W. Halley
G. A. Voth
R. Kawai
J. H. Weare
K. M. Rosso
D. Yuen

April 2006

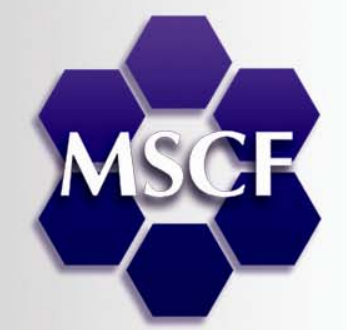


This research was performed in part using the Molecular Science Computing Facility (MSCF) in the William R. Wiley Environmental Molecular Sciences Laboratory, a national scientific user facility sponsored by the U.S. Department of Energy's Office of Biological and Environmental Research and located at the Pacific Northwest National Laboratory. Pacific Northwest is operated for the Department of Energy by Battelle.

\title{
DISCLAIMER
}

This report was prepared as an account of work sponsored by an agency of the United States Government. Neither the United States Government nor any agency thereof, nor Battelle Memorial Institute, nor any of their employees, makes any warranty, express or implied, or assumes any legal liability or responsibility for the accuracy, completeness, or usefulness of any information, apparatus, product, or process disclosed, or represents that its use would not infringe privately owned rights. Reference herein to any specific commercial product, process, or service by trade name, trademark, manufacturer, or otherwise does not necessarily constitute or imply its endorsement, recommendation, or favoring by the United States Government or any agency thereof, or Battelle Memorial Institute. The views and opinions of authors expressed herein do not necessarily state or reflect those of the United States Government or any agency thereof.

\author{
PACIFIC NORTHWEST NATIONAL LABORATORY \\ operated by \\ BATTELLE \\ for the
}

UNITED STATES DEPARTMENT OF ENERGY

under Contract DE-AC05-76RL01830

PNNL-15462 


\section{Computational Studies in Molecular Geochemistry and Biogeochemistry}
A. R. Felmy
J. R. Rustad
E. J. Bylaska
P. E. Smith
D. A. Dixon
T. P. Straatsma
M. Dupuis
G. A. Voth
J. W. Halley
J. H. Weare
R. Kawai
D. Yuen
K. M. Rosso

April 2006

Published by Pacific Northwest National Laboratory for the Environmental Molecular Sciences Laboratory 


\section{Computational Studies in Molecular Geochemistry and Biogeochemistry}

\section{$\underline{\text { Abstract }}$}

The ability to predict the transport and transformations of contaminants within the subsurface is critical for decisions on virtually every waste disposal option facing the Department of Energy (DOE), from remediation technologies such as in situ bioremediation to evaluations of the safety of nuclear waste repositories. With this fact in mind, the DOE has recently sponsored a series of workshops on the development of a Strategic Simulation Plan (SSP) on applications of high performance computing to national problems of significance to the DOE. One of the application areas selected was in the area of subsurface transport and environmental chemistry. Within the SSP on subsurface transport and environmental chemistry several areas were identified where applications of high performance computing could potentially significantly advance our knowledge of contaminant fate and transport. Within each of these areas molecular level simulations were specifically identified as a key capability necessary for the development of a fundamental mechanistic understanding of complex biogeochemical processes.

This effort consists of a series of specific molecular level simulations and program development in four key areas of geochemistry/biogeochemistry (i.e., aqueous hydrolysis, redox chemistry, mineral surface interactions, and microbial surface properties). By addressing these four different, but computationally related, areas it becomes possible to assemble a team of investigators with the necessary expertise in high performance computing, molecular simulation, and geochemistry/biogeochemistry to make significant progress in each area. The specific targeted geochemical/biogeochemical issues include:

Microbial surface mediated processes: the effects of lipopolysacchardies present on gramnegative bacteria.

Environmental redox chemistry: Dechlorination pathways of carbon tetrachloride and other polychlorinated compounds in the subsurface.

Mineral surface interactions: Describing surfaces at multiple scales with realistic surface functional groups

Aqueous Hydrolysis Reactions and Solvation of Highly Charged Species: Understanding the formation of polymerized species and ore formation under extreme (Hanford Vadose Zone and geothermo) conditions.

By understanding on a fundamental basis these key issues, it is anticipated that the impacts of this research will be extendable to a wide range of biogeochemical issues. Taken in total such an effort truly represents a "Grand Challenge" in molecular geochemistry and biogeochemistry. 


\section{$\underline{\text { Research Team Leader and Members }}$}

\section{Team Leader}

Name: R. Felmy

Institution: Pacific Northwest National Laboratory

$\underline{\text { Team Member }}$

\section{$\underline{\text { Institution }}$}

P. E. Smith

Kansas State University

E. J. Bylaska

Pacific Northwest National Laboratory

D. A. Dixon

M. Dupuis

Pacific Northwest National Laboratory

J. R. Rustad

Pacific Northwest National Lab

K. M. Rosso

Pacific Northwest National Laboratory

T. P. Straatsma

Pacific Northwest National Laboratory

R. Kawai

Pacific Northwest National Laboratory

J. H. Weare

University of Alabama at Birmingham

W. Halley

University of California, San Diego

D. Yuen

University of Minnesota

G. A. Voth

University of Minnesota

University of Utah

Number of Hours Allocated for the Past 3 Years

Year 1: 510,000

Year 2: 300,000

Year 3: 500,000

Total: $1,310,000$

Number of Hours Used During the Past 3 Years

Year 1: 275,000

Year 2: 360,000

Year 3: 500,000

Total: $1,135,000$

\section{Overview of the Past 3 Year's Accomplishments and Activities}

The "Computational Studies in Molecular Geochemistry and Biogeochemistry" highperformance computing grand challenge project has assisted several geochemistry/ biogeochemistry projects during the last year. In the following subsections, the activities and accomplishments of the four chosen thrust areas that benefited from the grand challenge computer time are described.

Microbial Membrane Modeling

The goal of this task is development of a theoretical understanding of the processes in subsurface environments that determine the uptake of ions by bacterial membranes and the adsorption of bacteria to geochemical surfaces. The task focuses on gram-negative bacteria, which are charac- 
terized by cell walls with outer leaflets consisting primarily of lipopolysaccharides (LPS). In the first year of the project, an accurate and consistent molecular model for the outer LPS membrane of Pseudomonas aeruginosa was developed. Interactions with a highly structured bacterial LPS membrane are quite different from those with a single LPS molecule, so efforts have focused on construction of a periodic assembly of LPS molecules to represent the membrane, rather than on individual LPS molecules. This approach provides a much more realistic model, and puts the project team in a unique position to address the following key questions with respect to the role and function of LPS membranes.

- How do LPS membranes attach to mineral surfaces? Are the O-antigen chains the primary functional units that determine geochemical surface adhesion, or are direct interactions between functional groups of the rough LPS membrane involved in adhesion? Is there a difference in surface adhesion as a result of strain-specific differences in saccharide composition of the core LPS region or A- or B-band antigen chains? Is there a specific role in surface adhesion from membrane proteins or small peptides at the cell surface? Because of the technological difficulties in getting bacteria to the locations in the subsurface where they are needed, an understanding of the main factors in adhesion is key to the development of effective remediation strategies.

- What is the role of LPS membranes in the transport of metal ions from mineral surfaces? How does the negatively charged surface of LPS membranes affect the interaction with mineral surfaces and the uptake of ions from the mineral surface?

- What is the affinity of binding sites in LPS membranes for ions other than $\mathrm{Ca}^{2+}$ ? Which ion binding sites in the membrane are accessible for exchange with solvated ions from the environment? What is the free energy of binding relative to $\mathrm{Ca}^{2+}$ of cations that have been identified to be taken up by the bacterial membrane? Does the preferential binding differ depending on the location of the binding site? Which functional groups near these binding sites determine this specificity?

\section{Environmental Redox Chemistry}

One of the more important degradation pathways for polychlorinated alkanes (PCAs) in the groundwater is the reductive dechlorination reaction hydrogenolysis. In this reaction, the PCA incorporates two electrons from a mineral surface, sulfide, quinone, or microbe to produce a polychlorinated alkane with hydrogen replacing chlorine, and a chloride ion being expelled. This two-electron transfer process is hypothesized to transpire in two sequential steps, with the first electron transfer forming a radical species and the second electron transfer having the newly formed radical incorporate a proton. The current consensus in the environmental science community is that the first electron transfer is the rate-limiting step, and several researchers have shown that strong correlations exist between thermodynamic descriptors of the first electron transfer process and the overall degradation rate. Hence, the one-electron reduction potential is expected to be a key thermodynamic descriptor for the degradation of PCAs. However, experimentally determined one-electron reduction potentials are known for only a small fraction of the 
thousands of possible hydrocarbons, and theoretical strategies used in environmental chemistry for estimating one-electron reductions potentials require extensive parameterization to be reliable.

Currently in environmental chemistry, the predominant way for estimating reduction potentials is to use structure activity relationships, such as Benson's group additivity method. These classical methods are known to be reasonably accurate. However, it difficult to systematically improve the accuracy of a group additivity method because it is difficult for them to explicitly account for neighboring interactions and long-range, through-bond effects. As a consequence, these methods are best used for interpolating properties of a homologous series of molecular species. Another way to estimate reduction potentials is to use $a b$ initio methods. Ab initio methods do not suffer from the neglecting neighboring interactions and have been shown too useful for calculating the thermodynamic properties for many types of species.

In this research, electronic structure methods were used to estimate the thermodynamics of adding one electron to a substantial number of PCAs, including non-substituted $\left(\mathrm{CH}_{\mathrm{x}} \mathrm{Cl}_{4-\mathrm{x}}\right)$ and substituted $\left(\mathrm{CH}_{\mathrm{x}} \mathrm{Cl}_{3-\mathrm{x}} \mathrm{N}\right.$, where $\left.N^{-}=\mathrm{F}^{-}, \mathrm{OH}^{-}, \mathrm{SH}^{-}, \mathrm{NO}_{3}{ }^{-}, \mathrm{HCO}_{3}{ }^{-}\right)$chlorinated methanes, and nonsubstituted and substituted DDT.

\section{Development of $A b$ Initio Methods for Mineral Surface Interactions}

In this project, a massively parallel code employing a state-of-the-art all-electron plane-wave DFT method has been developed, along with a plane-wave quantum mechanics/molecular mechanics (PW/MM) model that can be used to study important geochemical processes (structures and reactivity) at solvated redox-active natural mineral surfaces and interfaces. This work has resulted in the development of a significant number of algorithms and computer programs, including a state-of-the-art parallel projector augmented wave code.

\section{Aqueous Hydrolysis Reactions and Solvation of Highly Charged Species}

The properties of ions in aqueous solutions are of enormous importance to the interpretation of processes as diverse as biological function of proteins, subsurface transport, mineral formation, and the cleanup of toxic waste. In these systems the interaction of the ion with the surrounding water molecules leads to strong polarization that impacts all aspects of aqueous complexation. Understanding how molecular-level computational chemistry methods can help in identifying and developing models of aqueous speciation was the focus of this phase of the research.

A variety of studies have been performed in this research area. One of the major tasks focused on the polymerization of silica and the formation of mixed aluminum-silica-hydroxide species under high base conditions. Such solutions could form when highly basic aluminum containing solutions interact with subsurface silica containing minerals. This precise situation has occurred in the Hanford vadose zone where leaking tank waste has infiltrated the subsurface. Another of the major tasks focused on the solvation of $\mathrm{Fe}^{2+}, \mathrm{Fe}^{3+}$, and $\mathrm{Al}^{3+}$. Much of our molecular understanding of these hydrothermal solutions has been provided by x-ray adsorption fine structure experiments, which observe increasing ion-pair formation at elevated temperatures. However, the interpretation of these measurements usually requires some structural information about the solvation shell around the ions. Ab initio molecular dynamic (MD) simulations were used to 
probe the chemistry of the metal ion solvation shell as well as ion-pairing kinetics and stability as a function of temperature, pressure, and concentration.

\section{$\underline{\text { Publications }}$}

Alda, W, DA Yuen, H-P Luthi, and JR Rustad. 2000. "Exothermic and Endothermic Chemical Reactions Involving Very Many Particles Modeled with Molecular Dynamics." Physica D, 146(1-4):261-274.

Bylaska, EJ, M Valiev, and JH Weare. 2002. "Extended Solvation Structures: Results from Ab Initio Molecular Dynamic Simulations of $\mathrm{Al}^{3+}$ Charged Ions in Solution." (in preparation).

Bylaska, EJ, DA Dixon, AR Felmy, and PG Tratnyek. 2002. "One-Electron Reduction of Substituted Chlorinated Methanes as Determined from Ab Initio Electronic Structure Theory." J. Phys. Chem. A (in press).

Bylaska, EJ, M Valiev, R Kawai, and JH Weare. 2001. "Parallel Implementation of the Projector Augmented Plane Wave Method for Charged Systems.” Comp. Phys. Comm., 143:11-28.

Bylaska, EJ, DA Dixon, and AR Felmy. 2000. “The Free Energies of Reactions of Chlorinated Methanes with Aqueous Monovalent Anions: Application of Ab Initio Electronic Structure Theory." J. Phys. Chem., A, 104:610.

Felmy, AR, H Cho, JR Rustad, and MJ Mason. 2001. "An Aqueous Thermodynamic Model for Polymerized Silica Species to High Ionic Strength.” J. Sol. Chem., 30.

Gramada, A, JH Weare, and EJ Bylaska. 2002. "Pressure Induced Hydrogen Trapping in Water Clusters." (in preparation).

Gramada, A, JH Weare, and EJ Bylaska. 2001. "Molecular Dynamics Simulation of the Electron Solvation in Big Water Clusters." Maui High Performance Computing Center Application Briefs 2001.

Lins, RD and TP Straatsma. 2001. "Computer Simulations of the Lipopolysaccharide Membrane of Pseudomonas aeruginosa." Biophysical Journal, 81:1037-1046.

Rosso, KM and JR Rustad. 2001. "Structures and Energies of AlOOH and FeOOH Polymorphs from Plane Wave Pseudopotential Calculations.” American Mineralogist, 86:312-317.

Rustad, JR. 2001. "Molecular Models of Surface Relaxation, Hydroxylation, and Surface Charging at Oxide-Water Interfaces." Reviews in Mineralogy \& Geochemistry, 42:169-197.

Rustad, JR, DA Dixon, KM Rosso, and AR Felmy. 1999. "Trivalent Ion Hydrolysis Reactions: A Linear Free-Energy Relationship Based on Density Functional Electronic Structure Calculations." J. Am. Chem. Soc., 121:3234. 
Shroll, RM and TP Straatsma. "Molecular Basis for Microbial Adhesion to Geochemical Surfaces: Computer Simulation of Pseudomonas aeruginosa Adhesion to Goethite." Biophysical Journal (accepted for publication).

Shroll, RM and TP Straatsma. "Molecular Dynamics Simulations of the Goethite-Water Interface." Molecular Simulation (in press).

Shroll, RM and TP Straatsma. "Molecular Structure of the Outer Bacterial Membrane of Pseudomonas aeruginosa via Classical Simulation." Biopolymers (in press).

Valiev, M, EJ Bylaska, and JH Weare. 2002. "Bonding Structure of 3d Transition Metal Dimers with the Projector Augmented Plane Wave Method." J. Chem. Phys. (submitted).

Valiev, M, EJ Bylaska, A Gramada, and JH Weare. 2002. "First-Principles Molecular Dynamics," pages 1684-1734. Reviews in Modern Quantum Chemistry: A Celebration of the Contributions of RG Parr, Ed. KD Sen (World Scientific, Singapore).

\section{Contributed Presentations (Oral and Poster)}

Bylaska, EJ, JR Rustad, and M Dupuis. 2002. "Parallel Implementation of First-Principles Molecular Dynamics: Current and Future Technologies at PNNL.” CS\&E Initiative Seminar, March 6, 2002, Richland, Washington.

Bylaska, EJ, M Valiev, and JH Weare. 2002. "Extended Solvation Structures: Preliminary Results From $A b$ Initio Molecular Dynamic Simulations of $\mathrm{Al}^{3+}$ in Solution." American Chemical Society National Meeting, April 7-11, 2002, Orlando, Florida.

Bylaska, EJ, M Valiev, and JH Weare. 2002. "First-Principle Prediction of the Structure and Dynamics of Very Nonideal Aqueous Solutions: Ion Solvation and Proton Dynamics." EMSL 2002, May 21-22, 2002, Richland Washington.

Bylaska, EJ, E Apra, JR Rustad, M Dupuis, M Valiev, and JH Weare. 2002. "Current and Future Implementations of Band Structure and First-Principles Molecular Dynamics Programs in NWChem: Application to Chemical, Geochemical, and Biochemical Systems." EMSL 2002, May 21-22, 2002, Richland Washington.

Bylaska, EJ, M Valiev, and JH Weare. 2001. "Comparing the Accuracy and Efficiency of the Projector-Augmented Wave DFT Method (PAW) Against Gaussian Based DFT Methods." American Chemical Society National Meeting, April 1-5, 2001, San Diego, California.

Bylaska, EJ, M Valiev, and JH Weare. 2001. "PSPW Module (Pseudopotential Planewave Method)." Poster presented at Computational Chemistry Users Meeting, EMSL, June 18-19, 2001, Pacific Northwest National Laboratory, Richland Washington. 
Bylaska, EJ, M Valiev, JH Weare, and JR Rustad. 2001. "Comparing the Accuracy and Efficiency of the Projector-augmented Wave DFT Method (PAW) Against Gaussian Based DFT Methods." Workshop on Density Functional Theory for the Study of Complex Oxides, May 14-18, 2001, The Royal Institution of Great Britain, London, England.

Bylaska, EJ, DA Dixon, and AR Felmy. 2000. "The Free Energies of Reactions of Chlorinated Methanes with Aqueous Monovalent Anions: Application of Ab Initio Electronic Structure Theory." Spring 2000 ACS National Meeting, San Francisco, California.

Rustad, JR, and KM Rosso. 2000. "Total Energy Calculations of Iron and Aluminum Oxyhydroxide Bulk Phases and Surfaces.” MRS 2000 Spring Meeting, April 24, 2000, San Francisco, California.

Straatsma, TP. 2003. Special Session on Bacteria-Mineral Interactions, Spring American Chemical Society Meeting, March 17-23, 2003, New Orleans, Louisiana.

Straatsma, TP. 2002. "Modeling of the Rough LPS Membrane of Pseudomonas Aeruginosa." Symposium Computational Challenges of the Post-Genomic Age, March 2002, Durham, North Carolina.

Straatsma, TP. 2001. "Modeling of the Rough LPS Membrane of Pseudomonas Aeruginosa." Northwest Regional Meeting of the American Chemical Society, Seattle, Washington, June 14-17, 2001.

Straatsma, TP. 2000. "Molecular Modeling of Geochemical Reactions at Microbial Membranes." Department of Energy Geosciences Symposium, October 2000, Gaithersburg, Maryland.

Valiev, M, EJ Bylaska, and JH Weare. 2001. "Comparative Study of 3d Transition Metal Dimers Using Projector Augmented Plane Wave Method and NWChem." Computational Chemistry Users Meeting, June 18-19, 2001, EMSL, Pacific Northwest National Laboratory, Richland, Washington.

Valiev, M, EJ Bylaska, and JH Weare. 2001. "Parallel Implementation of First-Principles Molecular Dynamics: Applications to Large Simulation Problems." Computational Chemistry GRID Conference, October 16-17, 2001, University of Kentucky, Lexington, Kentucky.

Weare, JH, M Valiev, and EJ Bylaska. 2001. "First-Principles Dynamical Simulations of Hydrothermal Solution Behavior." $11^{\text {th }}$ Annual V.M. Goldschmidt Conference, May 2001, Hot Springs, Virginia.

Weare, JH, N Møller, Z Duan, and C Christov. 2001. “Thermodynamic Models of Natural Fluids: Theory and Practice." American Chemical Society National Meeting, April 1-5, 2001, San Diego, California. 


\section{Significant Methods/Routines or Codes Developed}

$\underline{\text { Parallel Projector Augmented-Wave Code }}$

The parallel projector augmented-wave (PAW) method is an all-electron approach that has many of the advantages of typical pseudopotential plane-wave (Car-Parrinello) approaches with the added ability to handle first-row elements with d electrons (Blochl 1994). The PAW method is based on the density functional approximation to the full Schrödinger equation in which each allelectron Kohn-Sham molecular orbital is defined in terms of a smooth wave function (expanded in plane-waves) and a core part (expanded using a radial grid about each atom).

\section{$\underline{\text { Implementing Free-Space Boundary Conditions Into Plane-Wave Methods }}$}

Highly accurate and efficient equations for implementing free-space boundary conditions into an existing periodic $a b$ initio plane-wave code has been developed and implemented. An algorithm that can modify an existing ab initio plane-wave molecular dynamics (MD) code (e.g., CarParrinello) to use free-space boundary conditions, instead of periodic boundary conditions, was also developed.

\section{$\underline{\text { Water Pseudopotentials for Plane-Wave Methods }}$}

In the process of developing a $\mathrm{QM} / \mathrm{MM}$ strategy for plane-wave programs, water pseudpotentials for use in plane-wave programs were also developed.

\section{$\underline{\text { Atomic Point Charge Analysis for Plane-Wave Methods }}$}

In the process of developing a $\mathrm{QM} / \mathrm{MM}$ strategy for plane-wave programs, a technique that converts density represented by plane-waves into a density represented by atom-centered Gaussian expansions was implemented. This approach has certain advantages over the model (pseudopotential) strategy; it was determined that this approach does not have enough flexibility in it to induce the correct polarization into the QM part from the MM part. However, conversion of the plane-wave density into atomic point charges was found to be a useful analysis tool, and this type of analysis has been included in the PNNL-developed NWChem program package.

\section{Development of a Parallel 3D FFT Based Upon a Hilbert Space Filling Curve}

The two-dimensional Hilbert parallel Fast Fourier Transform (FFT) was built from onedimensional FFTs and a parallel block rotation, and the program package FFTPACK was used to perform the one-dimensional FFTs. The Hilbert decomposition reduces the latency of the parallel block rotation to be proportional to the square root of the number of tasks used.

\section{$\underline{\text { Reference }}$}

Blochl, PE. 1994. "Projector Augmented-Wave Method.” Phys. Rev. B, 50(24):17953-17979. 


\section{Appendix A - Full Report of First Year Activities and Accomplishments}

\section{Molecular Modeling of the LPS Membrane of P. aeruqinosa}

Computational molecular modeling studies require the availability of a three-dimensional structure. For many biomolecular systems, such as proteins and DNA, such structures are available in publicly accessible databases. ${ }^{1}$ Such structures are generally determined by X-ray crystallography or nuclear magnetic resonance (NMR) spectroscopy. Unfortunately, for biological membranes, such structural information is not readily obtainable by these techniques. For the LPS membranes, construction of three-dimensional molecular models is required for the individual LPS molecules as well as the assembly of these molecules into a membrane arrangement. A three-dimensional structure of a single rough LPS molecule of P. aeruginosa is not available from experimental or theoretical sources, and had to constructed based on experimentally available sequence data for the LPS monomer. The recently published chemical structure of the wild-type strain PA01 of P. aeruginosa serotype O5, as determined by a combination one- and two-dimensional NMR and mass spectrometry experiments (Kulshin et al. 1991; Sadovskaya et al. 1998), was used. Schematic drawings of the chemical structure, molecular structure and calculated electrostatic potential are shown in Figure A.1. For the molecular modeling studies of the LPS membrane undertaken in this project, it was necessary to have an accurate charge model for the individual molecules, particularly because electrostatic interactions between the highly negatively charged LPS molecules and the $\mathrm{Ca}^{2+}$ cations are the
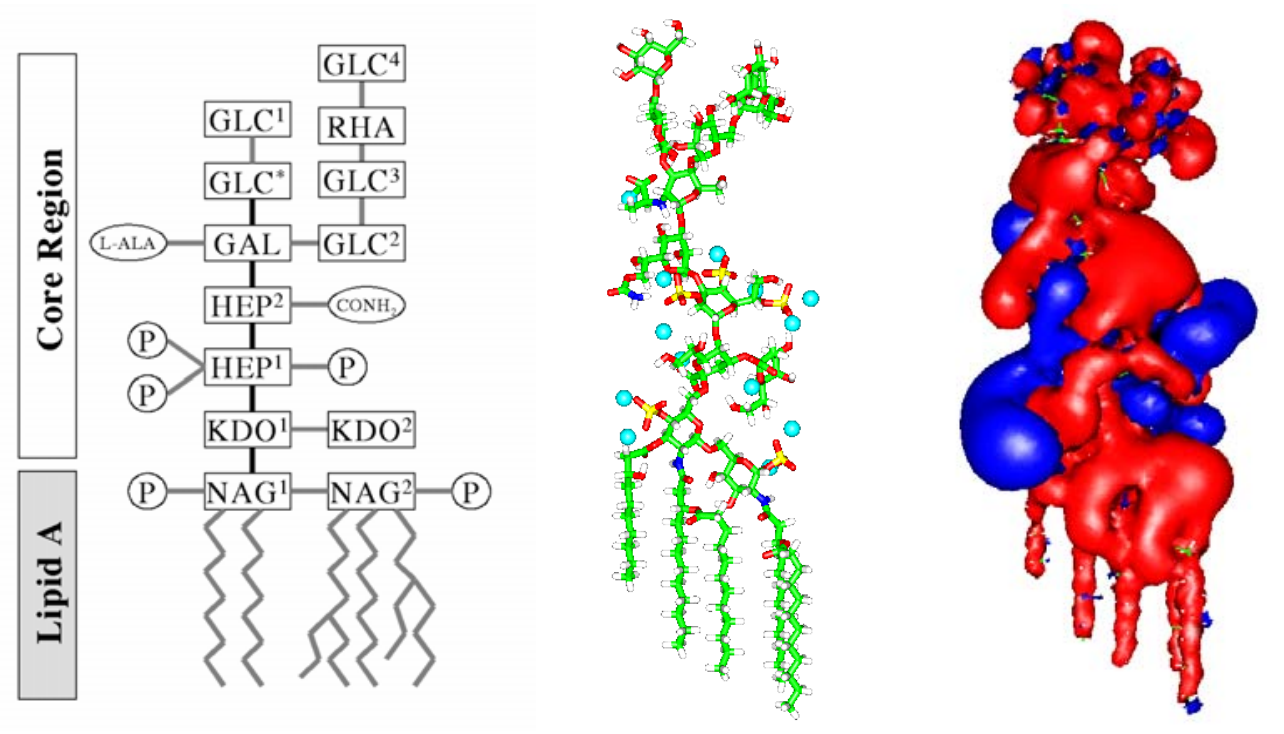

Figure A.1. Schematic drawing of the lipid-A and core polysaccharide regions (left), the molecular structure (middle), and the calculated electrostatic potential shown as the isocontours at $-100 \mathrm{mV}$ in red and $+100 \mathrm{mV}$ in blue (right) of the LPS of $P$. aeruginosa.

\footnotetext{
${ }^{1}$ Protein Data Bank, http://www.rcsb.org.
} 
main forces that maintain the integrity of the membrane. A charge model appropriate for use in membrane computer simulations was determined by stretching an LPS molecule and placing counter ions near the structure to neutralize the total charge.

For this geometry, with 481 atoms, electronic structure calculations were carried out at the Hartree Fock level with 6-31G* basis sets, using the recommended approach to obtain partial charges consistent with use of the AMBER force field (Cornell et al. 1995) that the project team used for the MD simulations. A highly efficient method was implemented to fit partial atomic charges to quantum mechanically determined electrostatic potentials as part of NWChem, (Harrison et al. 2001) the PNNL-developed suite of software for computational chemistry on massively parallel computers. This method is based on deriving the partial atomic charges that best reproduce the electrostatic potential on a grid outside the molecule evaluated from the electronic structure wave function. The implementation used by the project team allows such electrostatic fitting to be carried out efficiently for very large molecular systems. Initial calculations were performed for a model LPS molecule with 936 atoms, which was featured on the cover of Chemical \& Engineering News (2000). Similar structural model building and electrostatic fitting calculations were also performed for the phosphatidylethanolamine molecules of the inner leaflet. This approach is different from that usually employed for such classical MD simulations where the charges are taken from simple molecular fragments. The project team found that its approach of getting the charges of the whole system provides an improved set of charges over that obtained by using the small fragment approach.

A molecular model for the membrane was constructed by replication of an LPS molecule in a $4 \times 4$ arrangement, with sufficiently large intermolecular distances to allow molecular relaxation, including molecular rotations, during the equilibration phase of the MD simulations. Similarly, an inner leaflet of phospholipid molecules was constructed, and $\mathrm{Ca}^{2+}$ counter ions were placed for charge neutralization. As part of this project, a number of tools were built and included in the MD setup module of NWChem that enables these operations to be performed efficiently, as this is a very time-consuming process. Using the MD module of NWChem, the system was condensed to the proper density by application of anisotropic high-pressure scaling, solvated using the SPC/E water model (Berendsen 1987), and equilibrated. Details of this procedure have been published (Lins 2001).

Subsequently, molecular modeling studies of a model of the rough LPS membrane of $P$. aeruginosa were performed to 1) analyze the structural and dynamical properties of the polysaccharide core and 2) compare this result to experimental data to assess the validity of the model. Good agreement was obtained for the lipid layer density as measured by the surface area per phospholipid molecule compared to reported values for a phosphatidylethanolamine bilayer membrane (McIntosh et al. 2000). This property is reportedly very sensitive to the atomic charge model used in MD simulations (Schuler 2000), so the approach based on using NWChem and massively parallel computers to obtain the partial charges from a realistic model was important to getting a good set of parameters. Nanosecond MD trajectories for the 40,000-atom system were generated and analyzed using a variety of methods, including root mean square (RMS) deviations, energetic decomposition, water, ion and functional group distributions, and essential dynamics analysis (Amadei et al. 1993; Peters et al. 1996; van Aalten et al. 1997). The analysis of the molecular trajectories revealed two basic properties of the membrane that are 
significant for how this membrane potentially exchanges solvated metal ions, and how this membrane interacts with nearby surfaces. A distinctly different structure of the ion distribution was found for the inner core and outer core regions, as shown in Figure A.2. The arrangement of the phosphate and carboxylate groups in this region was shown to result in a highly structured inner core region and a more flexible solvent accessible region suitable for the exchange of ions with the external environment. In the inner core, the $\mathrm{N}$-acetyl-glucosamine lipid-A head groups form assemblies of four phosphate functional groups from different LPS molecules tightly held together by $\mathrm{Ca}^{2+}$ counter ions, providing a stable, nearly rigid arrangement of the inner core. Closer to the surface, phosphate groups of the heptose residues form more mobile strings linked by $\mathrm{Ca}^{2+}$ counter ions. This potential mobility has consequences for the accessibility of these binding LPS sites for hydrated ions from the environment. The second observation is the electrostatic gradient over the outer membrane of $100 \mathrm{mV}$, shown in Figure A.3, consistent with a potential difference of $85 \mathrm{mV}$ measured experimentally (Seidel et al. 1992). Analysis of the electrostatic potential at the surface of the LPS membrane shows significant structure, as seen in Figure A.3. These areas of negative potential were found to fluctuate rapidly in the MD simulations, suggesting that the membrane is highly adaptable to approaching solvated ions or mineral surfaces that are expected to have a much more rigid electrostatic signature.
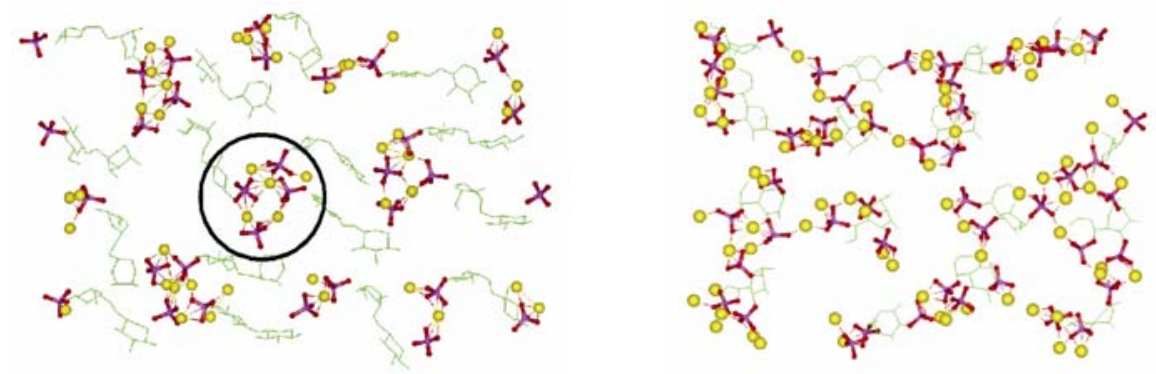

Figure A.2. Phosphate distribution in the inner (left) and outer core (right) polysaccharide region of the LPS membrane of $P$. aeruginosa, showing the clustering in the inner core such as the encircled cluster of phosphate groups, and the string arrangement in the outer core phosphate groups.
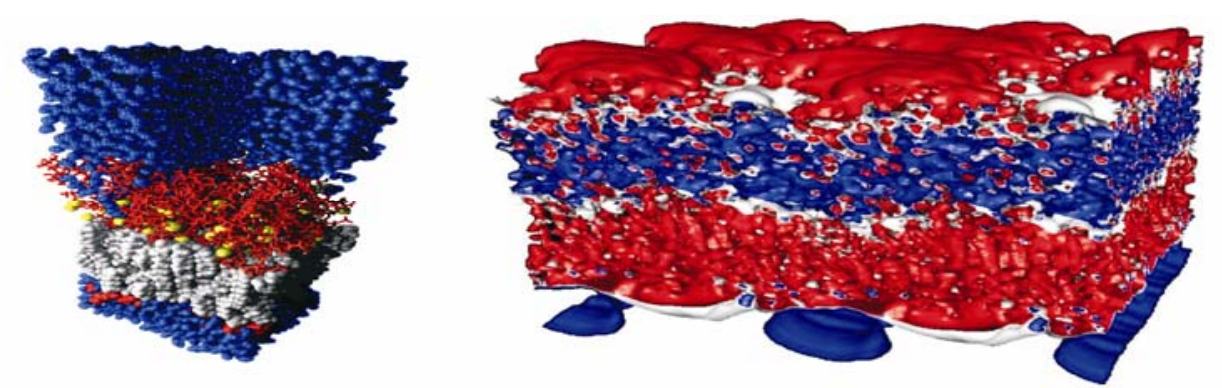

Figure A.3. Molecular structure (left) and electrostatic potential shown as the isocontours at $-100 \mathrm{mV}$ in red and $+100 \mathrm{mV}$ in blue (right) of the assembled LPS membrane of $P$. aeruginosa. 
Trivalent Ion Hydrolysis Reactions: A Linear Free-Energy Relationship Based on Density Functional Electronic Structure Calculations

Over 20 years ago, Baes and Mesmer (1976) suggested that if quantum mechanics were at a more advanced state, it might be possible to compute the stabilities of hydrolysis products directly, rather than by relying on a comparative chemical approach. In this work, the project team has shown that DFT calculations of the gas-phase hexaaquo ion deprotonation energies do provide a reasonable basis for understanding the relative aqueous acidities of the trivalent ions. The coherence of the calculated values also lends additional credence to the measured experimental values which can be uncertain because of the formation of multiple species in solution. This provides further confidence, motivation, and a means for developing a more fundamental understanding of the electronic structural effects which promote or inhibit hydrolysis. In addition, the success of the calculations performed here should carry over to the prediction of acid-base reactions involving polynuclear species and surfaces where bonding relationships are more complex.

The Free Energies of Reactions of Chlorinated Methanes with Aqueous Chlorintated Methanes with Aqueous Monovalent Anions: Application of Ab Initio Electronic Structure Theory

The presence of different anionic species in natural waters can significantly alter the degradation rates of chlorinated methanes and other organic compounds. Favorable reaction energetics are a necessary feature of these nucleophilic substitution reactions that can result in the degradation of the chlorinated methanes. In this study, $a b$ initio electronic structure theory was used to evaluate the free energies of reaction of a series of monovalent anionic species $\left(\mathrm{OH}^{-}, \mathrm{SH}^{-}, \mathrm{NO}_{3}{ }^{-}, \mathrm{HCO}_{3}{ }^{-}\right.$, $\mathrm{HSO}_{3}^{-}, \mathrm{HSO}_{4}^{-}, \mathrm{H}_{2} \mathrm{PO}_{4}^{-}$, and $\mathrm{F}^{-}$) that can occur in natural waters with the chlorinated methanes, $\mathrm{CCl}_{4}, \mathrm{CCl}_{3} \mathrm{H}, \mathrm{CCl}_{2} \mathrm{H}_{2}$, and $\mathrm{CClH}_{3}$. The results of this investigation showed that nucleophilic substitution reactions of $\mathrm{OH}^{-}, \mathrm{SH}^{-}, \mathrm{HCO}_{3}{ }^{-}$, and $\mathrm{F}^{-}$are significantly exothermic for chlorine displacement, $\mathrm{NO}_{3}{ }^{-}$reactions are slightly exothermic to thermoneutral, $\mathrm{HSO}_{3}{ }^{-}$reactions are slightly endothermic to thermoneutral and $\mathrm{HSO}_{4}{ }^{-}$, and $\mathrm{H}_{2} \mathrm{PO}_{4}{ }^{-}$reactions are significantly endothermic. In the case of $\mathrm{OH}^{-}, \mathrm{SH}^{-}$, and $\mathrm{F}^{-}$where there is limited experimental data, these results agree well with experiment (Table A.1). The results for $\mathrm{HCO}_{3}{ }^{-}$are potentially important given the near ubiquitous occurrence of carbonate species in natural waters. The calculations reveal that the degree of chlorination, with the exception of substitution of $\mathrm{OH}^{-}$, does not have a large effect on the Gibbs free energies of the substitution reactions. These results demonstrate that $a b$ initio electronic structure methods can be used to calculate the reaction energetics of a potentially large number of organic compounds with other aqueous species in natural waters and can be used to help identify the potentially important environmental degradation reactions.

\section{Implementing Free-Space Boundary Conditions Into Plane-Wave Methods}

The technique developed in this work gives $a b$ initio plane-wave methods the ability to deal with charged and polar molecules, clusters, and surfaces. In addition, the technique is critical for a proposed QM/MM method. Highly accurate and efficient equations have been developed for implementing free-space boundary conditions into an existing periodic ab initio plane-wave code. The project team has shown that, for problems in which the choice of boundary conditions was not important, the energies calculated using a modified free-space $a b$ initio plane-wave code could be directly compared to a conventional periodic $a b$ initio plane-wave code. Furthermore, 
it was shown that implementing free-space boundary conditions into an existing parallel periodic code would not significantly degrade its parallel efficiency. An algorithm that can modify an existing $a b$ initio plane-wave MD code (e.g., Car-Parrinello) to use free-space boundary conditions, instead of periodic boundary conditions, was also developed.

\section{Mixed Hamiltonian (PW/MM) Methods for Geochemical Electronic Structure Studies}

A combined plane-wave quantum mechanics/molecular mechanics (PW/MM) methodology to study important geochemical processes (structures and reactivity) at solvated redox-active natural mineral surfaces and interfaces is being developed. As pointed out in the Strategic Simulation Initiative Whitepaper on "Subsurface Transport and Environmental Chemistry," (http://www.emsl.pnl.gov/proj/geosciences/ssp.html) redox processes are one of the most important and least understood processes effecting the fate and transport of contaminants in the subsurface. The project consists of four development/simulation phases and this strategy will allow researchers, for the first time, to simulate geochemically important inferfacial processes that are not easily amenable to classical models. These include changes in oxidation states, changes in coordination and oxidation states (i.e., bond breaking and bond formation), and redox reactions of pollutants such as chlorinated hydrocarbons on iron-oxides and other environmentally important surfaces. The project team is combining the very powerful methodology of PW density functional method, namely Blochl's PAW formalism with the popular mixed Hamiltonian techniques of quantum chemistry to create a unique capability for a quantum treatment of increasingly complex and realistic models of interfacial processes. The model will include a quantum plane-wave description of the active site with a classical pseudopotential representation of underlying mineral lattices and solvent water molecules. The PAW formalism was selected because it is one of the most efficient $a b$ initio approaches for studying large systems, including transition metal atoms, with computational scaling of $\mathrm{N}^{2}-\mathrm{N}^{3}(\mathrm{~N}=$ number of atoms).

In the first phase of this code development, a massively parallel version of Blochl's PAW method was developed (see below). Currently, the PAW method is being expanded by incorporating a classical treatment of solvation effects. Most QM/MM methods that incorporate water molecules use point charges and van der Waals interactions to model the interactions between the $\mathrm{QM}$ and $\mathrm{MM}$ regions. Such a treatment is unphysical and not accurate when the water molecules are close to the QM region, because Pauli exclusion effects are neglected. A unique aspect of the QM/MM development of this project is to describe the water molecules by means of pseudopotentials. The third phase of the project will involve expanding the PAW method by incorporating Rustad et al.'s (1995) classical model for iron oxides. That phase, will involve development of accurate short-range electrostatic, dispersion, and covalent interactions between the QM and MM regions, which will include the development of electrostatic pseudopotentials and the scaling of covalent bond force constants at the QM/MM interface. 
Table A.1. Free Energies of reaction $(\mathrm{kcal} / \mathrm{mol})$ for the reactions of chlorinated methanes with aqueous chlorinated methanes with aqueous monovalent anions

\begin{tabular}{|c|c|c|c|c|c|}
\hline \multirow[b]{2}{*}{ Compounds } & \multicolumn{5}{|c|}{$\mathbf{D G}_{\mathrm{rxn}}$} \\
\hline & $\operatorname{Exp}$ & MP2/cc-pVDZ & LDA/DZVP2 & BP91/DZVP2 & B3LYP/DZVP2 \\
\hline $\mathrm{CCl}_{3} \mathrm{OH}$ & & -40.84 & -41.71 & -37.50 & -36.27 \\
\hline $\mathrm{CCl}_{2} \mathrm{HOH}$ & & -36.07 & -36.69 & -34.88 & -33.55 \\
\hline $\mathrm{CClH}_{2} \mathrm{OH}$ & & -28.44 & -29.00 & -27.81 & -27.51 \\
\hline $\mathrm{CH}_{3} \mathrm{OH}$ & -23.27 & & & & \\
\hline $\mathrm{CCl}_{3} \mathrm{SH}$ & & -27.06 & -25.99 & -22.76 & -21.433 \\
\hline $\mathrm{CCl}_{2} \mathrm{HSH}$ & & -24.34 & -24.34 & -22.05 & -20.446 \\
\hline $\mathrm{CClH}_{2} \mathrm{SH}$ & & -22.55 & -22.84 & -22.07 & -21.142 \\
\hline $\mathrm{CH}_{3} \mathrm{SH}$ & $-23.44^{\mathrm{a}}$ & & & & \\
\hline $\mathrm{CCl}_{3} \mathrm{NO}_{3}$ & & -6.71 & -1.25 & 0.70 & 4.67 \\
\hline $\mathrm{CCl}_{2} \mathrm{HNO}_{3}$ & & -7.58 & -3.61 & -1.51 & 0.24 \\
\hline $\mathrm{CClH}_{2} \mathrm{NO}_{3}$ & & -3.87 & -1.63 & -0.63 & -0.25 \\
\hline $\mathrm{CH}_{3} \mathrm{NO}_{3}$ & $-3.81^{\mathrm{a}}$ & & & & \\
\hline $\mathrm{CCl}_{3}\left(\mathrm{HCO}_{3}\right)$ & & -13.16 & -12.63 & -7.74 & -6.37 \\
\hline $\mathrm{CCl}_{2} \mathrm{H}\left(\mathrm{HCO}_{3}\right)$ & & -14.16 & -13.95 & -10.80 & -10.57 \\
\hline $\mathrm{CClH}_{2}\left(\mathrm{HCO}_{3}\right)$ & & -14.09 & -14.70 & -12.34 & -11.71 \\
\hline $\mathrm{CH}_{3}\left(\mathrm{HCO}_{3}\right)$ & $-11.39^{b}$ & & & & \\
\hline $\mathrm{CCl}_{3}\left(\mathrm{HSO}_{3}\right)$ & & -0.67 & 2.17 & 4.16 & 7.18 \\
\hline $\mathrm{CCl}_{2} \mathrm{H}\left(\mathrm{HSO}_{3}\right)$ & & 2.59 & 3.33 & 6.71 & 7.93 \\
\hline $\mathrm{CClH}_{2}\left(\mathrm{HSO}_{3}\right)$ & & 4.78 & 4.45 & 5.80 & 7.15 \\
\hline $\mathrm{CH}_{3}\left(\mathrm{HSO}_{3}\right)$ & $9.09^{\mathrm{c}}$ & & & & \\
\hline $\mathrm{CCl}_{3}\left(\mathrm{HSO}_{4}\right)$ & & 17.36 & 14.53 & 17.27 & 18.96 \\
\hline $\mathrm{CCl}_{2} \mathrm{H}\left(\mathrm{HSO}_{4}\right)$ & & 16.89 & 12.52 & 19.29 & 17.00 \\
\hline $\mathrm{CClH}_{2}\left(\mathrm{HSO}_{4}\right)$ & & 16.43 & 10.97 & 12.16 & 12.51 \\
\hline $\mathrm{CH}_{3}\left(\mathrm{HSO}_{4}\right)$ & $14.85^{\mathrm{c}}$ & & & & \\
\hline $\mathrm{CCl}_{3}\left(\mathrm{H}_{2} \mathrm{PO}_{4}\right)$ & & 5.59 & 5.73 & 11.37 & 12.94 \\
\hline $\mathrm{CCl}_{2} \mathrm{H}\left(\mathrm{H}_{2} \mathrm{PO}_{4}\right)$ & & 4.62 & 6.55 & 8.65 & 10.25 \\
\hline $\mathrm{CClH}_{2}\left(\mathrm{H}_{2} \mathrm{PO}_{4}\right)$ & & 8.60 & 7.99 & 9.91 & 10.35 \\
\hline $\mathrm{CH}_{3}\left(\mathrm{H}_{2} \mathrm{PO}_{4}\right)$ & $11.11^{\mathrm{c}}$ & & & & \\
\hline $\mathrm{CCl}_{3} \mathrm{~F}$ & -7.39 & -11.60 & -12.51 & -8.89 & -7.34 \\
\hline $\mathrm{CCl}_{2} \mathrm{HF}$ & -7.45 & -9.28 & -10.37 & -7.93 & -6.05 \\
\hline $\mathrm{CClH}_{2} \mathrm{~F}$ & -4.67 & -6.07 & -7.01 & -5.36 & -4.53 \\
\hline $\mathrm{CH}_{3} \mathrm{~F}$ & -0.94 & & & & \\
\hline \multicolumn{6}{|c|}{$\begin{array}{l}\text { a. MP2/cc-pVDZ values were used for the solvation energy of } \mathrm{CH}_{3} \mathrm{~N} \text { and } \mathrm{CClH}_{3} \text {, and experimental values were used for } \\
\text { the gas-phase Gibbs free energy of formation of } \mathrm{CH}_{3} \mathrm{~N} \text { and } \mathrm{CClH}_{3} \text {. } \\
\text { b. MP2/cc-pVDZ values were used for the solvation energy of } \mathrm{CH}_{3} \mathrm{~N} \text { and } \mathrm{CClH}_{3} \text {, experimental value was used for the } \\
\text { gas-phase Gibbs free energy of formation of } \mathrm{CCl} 3 \mathrm{H} \text {, experimental value was used for the enthalpy of formation of } \\
\mathrm{CH} 3 \mathrm{~N} \text {, and a MP2/cc-pVDZ values was used for the entropy. } \\
\text { c. MP2/cc-pVDZ values were used for the solvation energy of } \mathrm{CH}_{3} \mathrm{~N} \text { and } \mathrm{CClH}_{3} \text {. G2 theoretical and MP2/cc-pVDZ } \\
\text { values were used respectively for the gas-phase enthalpy and entropy of formation of } \mathrm{CH}_{3} \mathrm{~N} \text {. Experimental value was } \\
\text { used for the gas-phase Gibbs free energy of formation of } \mathrm{CClH}_{3} \text {. }\end{array}$} \\
\hline
\end{tabular}

\section{Water Pseudopotentials For Plane-Wave Methods}

Water pseudpotentials for use in plane-wave programs have been developed. The results obtained from their use suggest that these water pseudopotentials are numerically stable and induce the correct polarization into the QM system (see Figure A.5).

A water pseudpotential also was developed for use in the PAW code and the PSPW module of NWChem. The pseudopotential uses a flexible MM water, and the use of polarizable potentials 
is being explored. Mixed Hamiltonian methods allow more realistic representations of complex chemically active systems via lower level representations of the embedding environment. The current model is based on the pseudopotential developed by Barnett et al. (1987). However, Barnett et al.'s water pseudopotential contains several discontinuities that result in inaccurate atomic and molecular forces. To remove these discontinuities, the water pseudopotential was reformulated in terms of its short-range and long-range components. The short-range components are represented in terms of a linear combination of atom-centered gaussian functions

$$
\mathrm{V}_{\mathrm{sr}}(\overrightarrow{\mathrm{r}})=\sum_{\mathrm{j}=\mathrm{O}, \mathrm{H1}, \mathrm{H} 2} \sum_{\gamma} \mathrm{c}_{\gamma}^{\mathrm{j}} \mathrm{g}_{\gamma}\left(\left|\overrightarrow{\mathrm{r}}-\overrightarrow{\mathrm{R}}_{\mathrm{j}}\right|\right)
$$

and the long-range components are of the form

$$
V_{l r}(\vec{r})=-\sum_{j=O, H 1, H 2} q_{j} \frac{\operatorname{erf}\left(\frac{\left|\vec{r}-\vec{R}_{j}\right|}{R \text { cut }}\right)}{\left|\vec{r}-\vec{R}_{j}\right|}-\frac{1}{2} \alpha \frac{\operatorname{erf}\left(\left(\frac{\left|\vec{r}-\vec{R}_{O}\right|}{R p}\right)^{4}\right)}{\left|\vec{r}-\vec{R}_{O}\right|^{4}} .
$$

To generate the short-range coefficients $\left(c_{\gamma}^{j}\right)$, a weighted, least-squares fit is used (see Figure A.6).

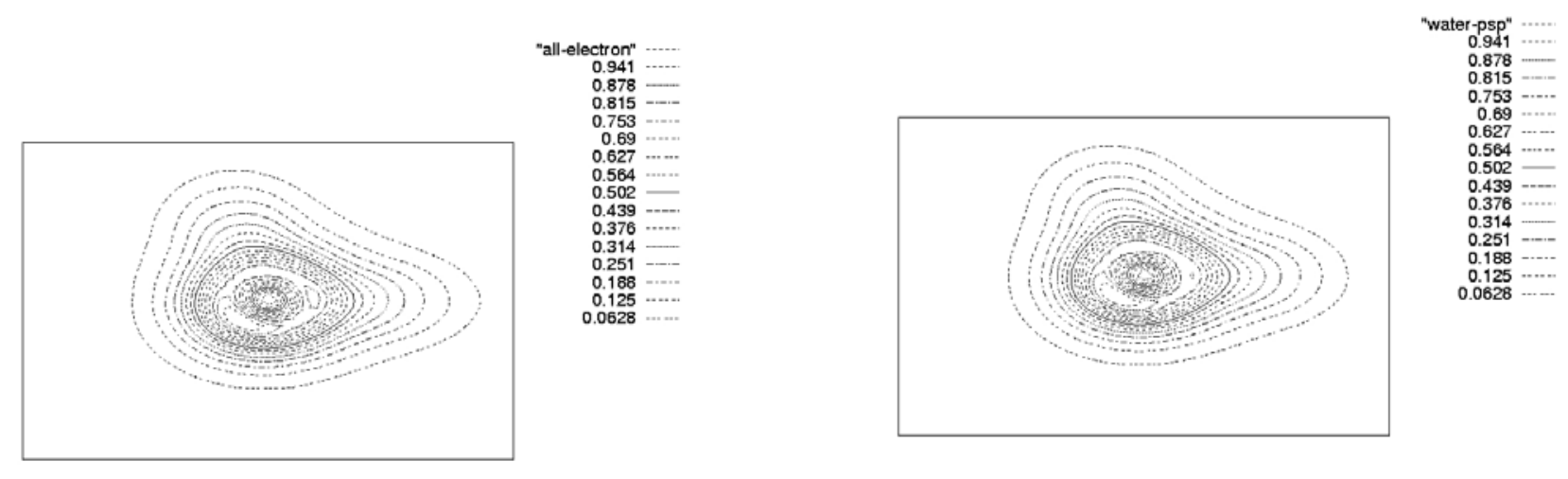

Figure A.5. Comparison of the density polarization from a water molecule described by QM (left figure) and by a pseudopotential (right figure). Each contour plot shows the electron density of a water molecule polarized by another water molecule (QM and pseudopotentia). The O-O distance between the two water molecules was $\mathrm{R}=2.7 \AA$. 

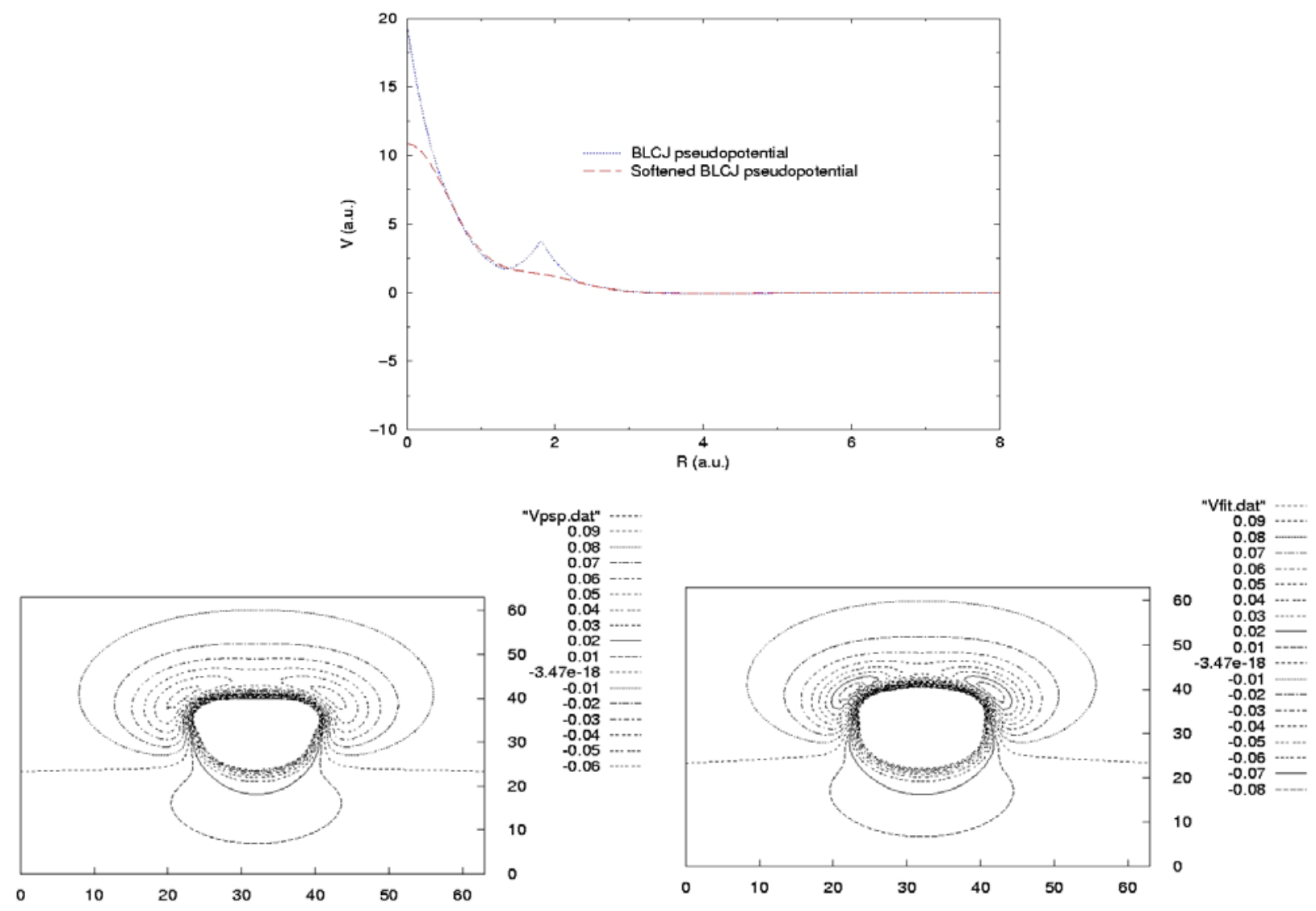

Figure A.6. Comparison of original water pseudopotential of Landaman et al. (1987) (BLCJ) and the softened BLCJ water pseudopotential. The top graph shows the pseudopotentials along the $\mathrm{O}-\mathrm{H}$ bond. The bottom left contour plot is the BLCJ pseudopotential and the bottom right contour plot is a softened BLCJ water pseudopotential.

\section{References}

Amadei, A, ABM Linssen, and HJC Berendsen. 1993. "Essential Dynamics of Proteins." Proteins, 17:412-425.

Baes, CF, Jr. and RE Mesmer. 1976. “The Hydrolysis of Cations.” Wiley, New York.

Berendsen, HJC, JR Grigera, and TP Straatsma. 1987. "The Missing Term in Effective Pair Potentials." J. Phys. Chem., 91:6269-6271.

Chemical and Engineering News. April 24, 2000.

Cornell, WD, P Cieplak, CI Bayly, IR Gould, KM Merz, DM Ferguson, DC Spellmeyer, T Fox, JW Caldwell, and PA Kollman. 1995. "A Second Generation Force Field for the Simulation of Proteins, Nucleic Acids, and Organic Molecules.” J. Am. Chem. Soc., 117: 5159-5197. 
Harrison, RJ, JA Nichols, TP Straatsma, M Dupuis, EJ Bylaska, GI Fann, TL Windus, E Apra, J Anchell, D Bernholdt, P Borowski, T Clark, D Clerc, H Dachsel, B de Jong, M Deegan, K Dyall, D Elwood, H Fruchtl, E Glendenning, M Gutowski, A Hess, J Jaffe, B Johnson, J Ju, RA Kendall, R Kobayashi, R Kutteh, Z Lin, R Littlefield, X Long, B Meng, J Nieplocha, S Niu, M Rosing, G Sandrone, M Stave, H Taylor, G Thomas, J van Lenthe, K Wolinski, A Wong, and Z Zhang. 2001. "NWChem, A Computational Chemistry Package for Parallel Computers, Version 4.0.1.” Pacific Northwest National Laboratory, Richland, Washington.

Kulshin, VA, U Zahringer, B Lindner, KE Jager, BA Dmitriev, and ET Rietschel. 1991. "Structural Characterization of the Lipid A Component of Pseudomonas aeruginosa Wild-type and Rough Mutant Lipopolysaccharides.” Eur. J. Biochemistry, 198:697-704.

Lins, RD and TP Straatsma. 2001. "Computer Simulation of the Rough Lipopolysaccharide Membrane of Pseudomonas aeruginosa.” Biophysical J., 81:1037-1046.

McIntosh, TJ and SA Simon. 1986. "Area Per Molecule and Distribution of Water in Fully Hydrated Dilauroylphosphatidylethanolamine Bilayers.” Biochemistry, 25:4948-4952.

Peters, GH, DMF van Aalten, O Edholm, S Toxvaerd, and R Bywater. 1996. "Dynamics of Proteins in Different Solvent Systems: Analysis of Essential Motion in Lipases." Biophys. J., 71:2245-2255.

Rustad, JR, BP Hay, JW Halley. 1995. "Molecular Dynamics of Iron (III) and Its Hydrolysis Products in Aqueous Solution." J. Chem. Phys., 102:427-431.

Sadovskaya, I, JR Brisson, JS Lam, JC Richards, and E Altman. 1998. "Structural Elucidation of the Lipopolysaccharide Core Regions of the Wild-type Strain PA01 and O-chain-deficient Mutant Strains AK1401 and AK1012 from Pseudomonas aeruginosa Serotype O5." Eur. J. Biochemistry, 255:673-684.

Schuler, LD. 2000. "Molecular Dynamics Simulation of Aggregates of Lipids: Development of Force Field Parameters and Application to Membranes and Micelles." Ph.D. thesis.

Seidel, U, W Eberstein, G Schroder, and K Brandenburg. 1992. "Electrostatic Potential Barrier in Asymmetric Planar Lipopolysaccharide/Phospholipid Bilayers Probed with the ValinomycinK+ Complex." Z. Naturforschung, 47:757-761.

Van Aalten, DMF, JBC de Groot, JBC Findkay, and HJC Berendsen. 1997. "A. Amadei, A Comparison of Techniques for Calculating Protein Essential Dynamics." J. Comput. Chem., 18:169-181. 


\section{Appendix B - Full Report of Second Year Activities and Accomplishments}

\section{Design of a Molecular Model for Goethite}

One of the main goals of this project is to provide the capability for modeling the interaction of bacterial membranes with mineral surfaces, in order to provide a molecular level insight into the interactions of bacteria with the subsurface environment. To achieve this goal, the project team developed a molecular model for the goethite that is consistent with the force field used for the biomolecular simulations of the membrane. Molecular simulations of the bacterial membrane were carried out for small assemblies of molecules, subject to periodic boundary conditions. The same representation was also used for the simulation of mineral surfaces. However, the compressibility of the membrane and the mineral in the lateral direction is significantly different, which can lead to significant technical difficulties in simulations of a system consisting of the membrane in contact with a mineral surface, particularly in simulations in constant pressure ensembles. To overcome this problem, the project team set out to design a model for mineral fragments using a parameterization that maintains as much of the bulk behavior as possible. In addition, for simulations of membranes in near contact with a mineral surface, this approach allows for the solvent and solvated ions to move into or out of the interlayer region. Only to a limited extent would it be possible to simulate such processes using non-constant particle ensemble dynamics.

The three-dimensional structure of the goethite mineral used in this work exposes the 110 surface. $^{1}$ The development of an accurate potential for the mineral surface is the crucial step in the design of the fragment model. Because a model is needed that captures significant bulk mineral behavior, parameters were determined for a small mineral fragment (as shown in Figure B.1) as well as for a periodic mineral slab. The small mineral fragment was parameterized to reproduce the electrostatic potential of an infinite mineral surface while minimizing edge effects. Partial atomic charges on the mineral fragment were determined by electrostatic
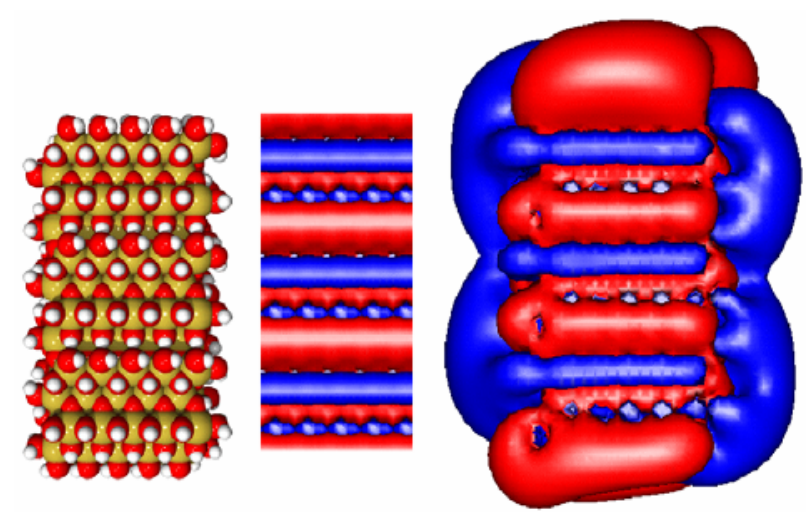

Figure B.1. Geothite mineral fragment (left), electrostatic potential of a periodic mineral (middle), and electrostatic potential of the mineral fragment (right).

${ }^{1}$ J.R. Rustad, goethite mineral model. 
potential fitting using the electrostatic potential calculated from two-dimensional Hartree-Fock calculations of a mineral slab. Parameters for bond-stretches, angular bending, torsions, and van der Waals interactions were adopted from the AMBER force field. This procedure resulted in a fragment model for the mineral with partial atomic charges that reproduced the electrostatic potential of the bulk mineral rather than that of a small cluster.

MD simulations of the mineral fragment and a periodic mineral layer in contact with water were carried out to test our parameterization. From analyses of radial distribution functions and dipole orientations, the behavior of solvent molecules located directly above the 110 surface of the mineral fragment agrees very well with the behavior of solvent above the periodic mineral slab.

$\underline{\text { Simulations of Solvated } \mathrm{Fe}^{2+}, \mathrm{Fe}^{3+} \text {, and } \mathrm{Al}^{3+} \text { : Proton Dynamics in the Ion Solvation Region }}$

During FY 2001, studies on $\mathrm{Fe}^{2+}, \mathrm{Fe}^{3+}$, and $\mathrm{Al}^{3+}$ cations in solution began. These highly charged metal ions form quite stable solvation shells and the current consensus from experimental data is that stable octahedral complexes exist for all first row transition metal cations, except $\mathrm{Cr}^{2+}$ and $\mathrm{Cu}^{2+}$, which display significant Jahn-Teller distortions. In some cases (e.g., $\left.\mathrm{Cu}^{2+}\right)$, the distortion is so great as to have the system adopt a fivefold configuration instead of a $4+2$ configuration (Pasquarello et al. 2001). There is also a possibility of Jahn-Teller distortions for other transition metal cations and evidence indicates that in the case of $\mathrm{Fe}^{2+}$ system as shown Figure B.2. Preliminary calculations indicate the formation of an axially distored octahedral complex. However, no evidence was found for an unusual coordination in this system.
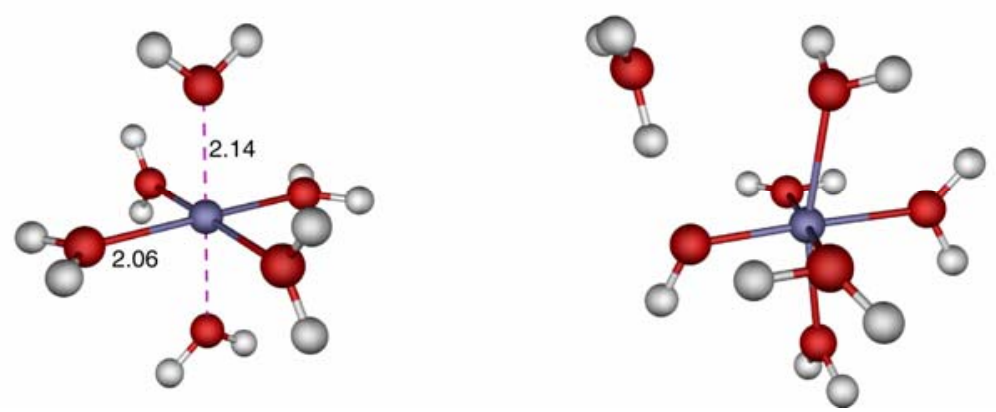

Figure B.2. Right: fully optimized structure of $\mathrm{Fe}^{2+}\left(\mathrm{OH}_{2}\right)_{6}$ cluster using PAW approach; left: edge bond coordination of second shell water molecules for $\mathrm{Fe}^{2+}$ water complex.

The nature of dynamical process within the solvation shell is also of interest, particularly the mobility of protons in the solvation shell (transient hydrolysis) and their transfer between the first and second solvation shells. Experimental data indicate that, for trivalent transition metal cations, the water molecule residence time varies from $10^{-3}$ seconds to several seconds in $\mathrm{Cr}^{3+}$. However, NMR and QENS experiments (Salmon et al. 1990; Gerdman 1990; Salmon et al. 1989, 1992, 1987; Chmelnik 1972) indicate that there is a much faster proton motion in the system $\left(10^{-5}\right.$ to $10^{-9}$ seconds). In a previous investigation of the $\mathrm{Al}^{3+}$ system, the project team showed through simulation that at high temperatures the protons in the first shell exchanged rapidly to receiving sites in the second solvation shell on a time scale much shorter than that of the lifetime of a water molecule in the first solvation shell (Lubin et al. 2000). During FY 2001, extensive 
simulations in bulk water were performed, and the simulations were extended to $\mathrm{Fe}^{2+}$ and $\mathrm{Fe}^{3+}$. An example of the proton transfer is shown in Figure B.3. The mechanism of exchange of transient hydrolysis agrees qualitatively with NMR measurements. The simulations performed by the project team also suggest a reverse temperature effect in which the proton exchange becomes slower at higher temperatures due to the entropic un-alignment of waters between the second and the first solvation shells. A manuscript describing this work is in preparation.
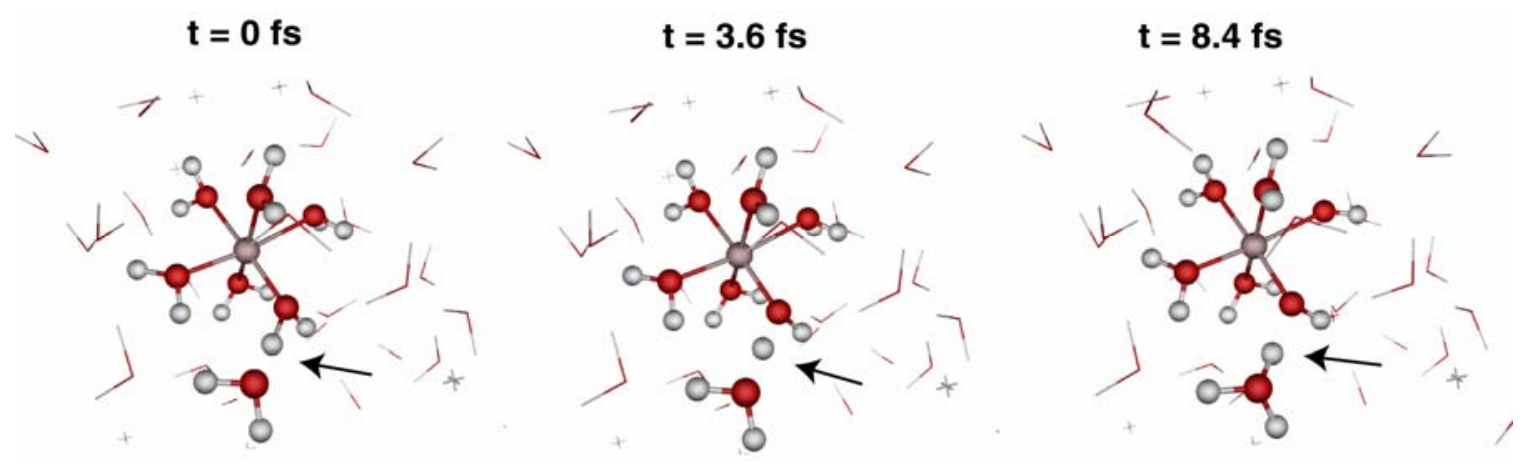

Figure B.3. Snapshots of proton migration in AIMD simulation of $\mathrm{Al}^{3+}\left(\mathrm{H}_{2} \mathrm{O}\right)_{33}$ system.

Understanding the Formation of Polymerized Species Under Extreme Conditions

Geochemical models used to predict dissolved metal concentrations can be unreliable in highly basic concentrated electrolyte solutions. Such chemical systems are of particular importance in the area of leaking tank wastes at Hanford Site and other U.S. Department of Energy sites. In this regard, the project team has begun molecular-level simulations of the structures and energetics of mononuclear and polynuclear hydrolysis species containing Si(IV) species. Such species are likely to form when highly basic solutions (i.e., tank wastes) contact siliceous minerals in the subsurface. Understanding the formation of such polymerized species, as well as the factors that may inhibit formation (e.g., concentrations of other species, such as phosphate and sulfate) will not only contribute to the development of more accurate aqueous solution models but will also help to better understand the processes of nucleation and growth of aluminum oxyhydroxide and alumina silicate minerals in these extreme environments.

Under highly basic conditions Si(IV) can form a wide range of monomeric and polymeric species ranging from simple monomers to cubic octamers (Sjoberg et al. 1985; Svensson et al. 1986). These, species, which often are highly charged, have also been shown to interact strongly with environmentally important species such as $\mathrm{Sr}$ and $\mathrm{Eu}$ (a trivalent actinide analog), thus increasing the solubility of the important solid phases of these elements [i.e., $\mathrm{SrCO}_{3}(\mathrm{c})$ and $\left.\mathrm{Eu}(\mathrm{OH})_{3}\right]$. Unfortunately, the solution phase concentrations of these elements are too low to identify the specific anionic silica species that are complexing the Sr and Eu via NMR or other techniques. Therefore, molecular modeling simulations of the expected anionic silica species have been initiated to help in identifying the strongest complexing silica species and help better interpret the NMR measurements. 
$A b$ initio structural optimizations (using DFT) have been performed, and NMR spectra have been calculated for numerous gas phase $\mathrm{Si}(\mathrm{IV})$ clusters including monomers $\left(\mathrm{H}_{3} \mathrm{SiO}_{4}{ }^{-}, \mathrm{H}_{2} \mathrm{SiO}_{4}{ }^{2-}\right)$, dimers $\left(\mathrm{Si}_{2} \mathrm{O}_{3}(\mathrm{OH})_{4}{ }^{2-}, \mathrm{Si}_{2} \mathrm{O}_{2}(\mathrm{OH})_{5}^{-}\right)$, trimers $\left(\mathrm{Si}_{3} \mathrm{O}_{6}(\mathrm{OH})_{3}{ }^{3-}\left(\right.\right.$ cyclo), $\mathrm{Si}_{3} \mathrm{O}_{5}(\mathrm{OH})_{5}{ }^{3-}$ (linear), tetramers $\left(\mathrm{Si}_{4} \mathrm{O}_{7}(\mathrm{OH})_{5}^{3-}, \mathrm{Si}_{4} \mathrm{O}_{8}(\mathrm{OH})_{4}{ }^{4-}\right)$, which are believed to be representative of species in solution. In addition, calculations have been initiated of these anionic species with divalent $\mathrm{Sr}^{2+}$ in a wide range of configurations, including single ligand, two ligand, and three ligand combinations (e.g., $\left.\mathrm{SrH}_{3} \mathrm{SiO}_{4}{ }^{+}, \mathrm{Sr}_{2}\left(\mathrm{H}_{3} \mathrm{SiO}_{4}\right)_{2}(\mathrm{aq}), \mathrm{Sr}\left(\mathrm{H}_{3} \mathrm{SiO}_{4}\right)_{3}{ }^{-}\right)$in the gas phase. Simulations have also been initiated in defining the solvation effects using Car-Parinello methods. In these simulations, $\mathrm{Si}(\mathrm{IV})$ clusters optimized in the gas phase were placed in a periodic supercell and explicitly solvated with up to 20 water molecules and a Na cation. So far, these explicit solvation simulations have produced no major structural changes in the gas-phase calculated $\mathrm{Si}(\mathrm{IV})$ species (e.g., Figure B.4). However, the project team has used these results to help develop a thermodynamic model of the solution phase reactions of Si monomers and polymers. A manuscript detailing this work appeared in the Journal of Solution Chemistry 30 (2001).

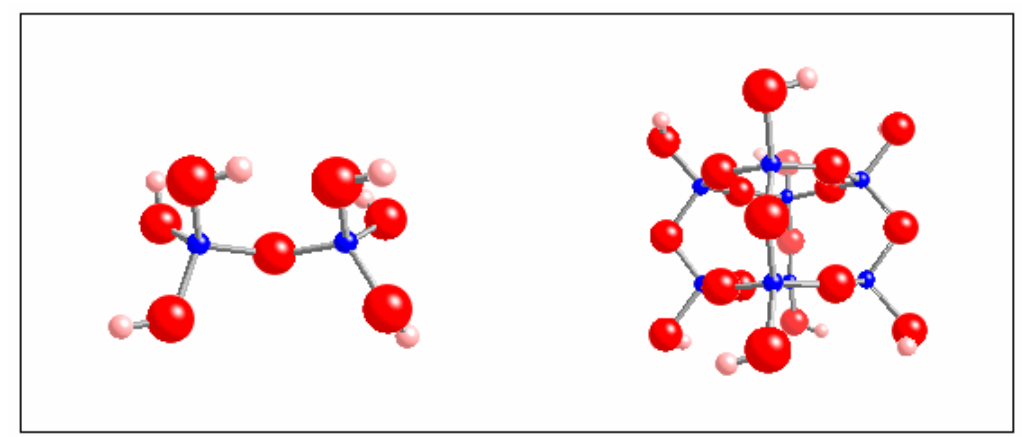

Figure B.4. The dimer and octomer $\mathrm{Si}(\mathrm{IV})$ polynuclear species.

The project team also initiated simulations to identify the specific mechanisms responsible for the polymerization process. These calculations are important in determining intermediate species and reaction rates in solution. This year the focus has been on the dimerization reaction, with a specific interest in whether the mechanism occurs via an $\mathrm{S}_{\mathrm{N}} 2$ mechanism. In this regard, simulations of the energetics of a deprotonated $\mathrm{H}_{3} \mathrm{SiO}_{4}{ }^{-}$species displacing a hydroxyl from the neutral silicic acid species are being performed. These simulations are ongoing. The $\mathrm{S}_{\mathrm{N}} 2$ reaction pathway simulations have produced an unexpected result. Ab initio gas phase and explicitly solvated calculations have shown an unexpected stability of the fivefold coordinated $\mathrm{Si}(\mathrm{V})$ intermediates. These unanticipated results led to adjustments in the project's MD models.

\section{One-Electron Reduction of Polychlorinated Solvents and Pesticides}

One of the more important degradation pathways for PCAs in the groundwater is the reductive dechlorination reaction hydrogenolysis. In this reaction, the PCA incorporates two electrons from a mineral surface, sulfide, quinone, or microbe to produce a PCA with hydrogen replacing a chlorine and a chloride ion being expelled. This two-electron transfer process is hypothesized to transpire in two sequential steps, with the first electron transfer forming a radical species and the second electron transfer having the newly formed radical incorporate a proton. The current consensus in the environmental science community is that the first electron transfer is the ratelimiting step, and several researchers have shown that strong correlations exist between 
thermodynamic descriptors of the first electron transfer process and the overall degradation rate. Hence, the one-electron reduction potential is expected to be a key thermodynamic descriptor for the degradation of polychlorinated alkanes. However, experimentally determined one-electron reduction potentials are known for only a small fraction of the thousands of possible hydrocarbons, and theoretical strategies used in environmental chemistry for estimating one-electron reductions potentials require extensive parameterization to be reliable.

Currently in environmental chemistry, the predominant way for estimating reduction potentials is to use structure activity relationships, such as Benson's group additivity method. These classical methods are known to be reasonably accurate. However, it difficult to systematically improve the accuracy of a group additivity method since it is difficult for them to explicitly account for neighboring interactions and long-range, through-bond effects. It is generally the case that group additivity methods are subject to large errors in heavily branched species, where neighboring steric effects are important, and in species containing very electronegative groups such as $\mathrm{NO}_{2}$ and F. For example, simple group additive methods do not work well for distinguishing differences between isomeric species, since these differences are a result of large steric effects. As a consequence, these methods are best used for interpolating properties of a homologous series of molecular species. Another way to estimate reduction potentials is to use $a b$ initio methods, which do not suffer from the neglecting neighboring interactions and have been shown to useful for calculating the thermodynamic properties for many types of species. The drawbacks of these methods are that they require significant computational resources and effective strategies to account for the correlation energy of a molecule. However, advances and improvements in computer hardware and $a b$ initio electronic structure software are mitigating these drawbacks.

In this work, the project team estimated the thermodynamics of adding one electron to nonsubstituted $\left(\mathrm{CH}_{\mathrm{x}} \mathrm{Cl}_{4-\mathrm{x}}\right)$, and substituted $\left(\mathrm{CH}_{\mathrm{x}} \mathrm{Cl}_{3-\mathrm{x}} \mathrm{N}\right.$, where $\left.\mathrm{N}^{-}=\mathrm{F}^{-}, \mathrm{OH}^{-}, \mathrm{SH}^{-}, \mathrm{NO}_{3}^{-}, \mathrm{HCO}_{3}^{-}\right)$ chlorinated methanes using ab initio electronic structure theory, canonical ensemble entropy formulas, and self-consistent reaction field theory for solvent effects. These potential pollutants are worth bearing in mind because they may well be present in natural waters contaminated with the industrially important chlorinated methanes. Moreover, the project team incorporated the bulky 4,4'-DDT molecule (i.e., $\mathrm{CCl}_{3} N$, where $N=\mathrm{CH}\left(\mathrm{C}_{6} \mathrm{H}_{4} \mathrm{Cl}\right)_{2}{ }^{-}$) at the end of the study to demonstrate that the $a b$ initio techniques used in this study and in the previous study are capable of being applied to large pollutants. This set of species contains species with different neighboring interactions and through-bond effects, and so represent a non-trivial set. Four possible product pathways for the first one-electron reductive step are considered in this study.

$$
\mathrm{CH}_{\mathrm{x}} \mathrm{Cl}_{3-\mathrm{x}} N+1 \mathrm{e}^{-} \rightarrow\left\{\begin{array}{rr}
\mathrm{CH}_{\mathrm{x}} \mathrm{Cl}_{2-\mathrm{x}} N+\mathrm{Cl}^{-} \text {(pathway 1) } \\
\mathrm{CH}_{\mathrm{x}} \mathrm{Cl}_{3-\mathrm{x}}+N^{-} \text {(pathway 2) } \\
\mathrm{CH}_{\mathrm{x}} \mathrm{Cl}_{2-\mathrm{x}} N^{-}+\mathrm{Cl} \text { (pathway 3) } \\
\mathrm{CH}_{\mathrm{x}} \mathrm{Cl}_{3-\mathrm{x}}^{-}+N & \text { (pathway 4) }
\end{array} \quad \forall x=0,1,2\right.
$$

Pathways 1 and 2 are expected to be the most likely pathways, because the electron affinities of $\mathrm{Cl}$ and $\mathrm{N}$ are expected to be greater than for $\mathrm{CH}_{\mathrm{x}} \mathrm{Cl}_{2-\mathrm{x}} \mathrm{N}$ and $\mathrm{CH}_{\mathrm{x}} \mathrm{Cl}_{3-\mathrm{x}}$. Notwithstanding this chemical prejudice, thermodynamic estimates for the reactions where the leaving group is a radical instead of an anion are also provided. Following the strategy of the previous study, separate computation steps are used to estimate electronic energy differences, entropy differences, and 
solvation energy differences. First, the enthalpies of formation of gas-phase radical $\mathrm{CH}_{\mathrm{x}} \mathrm{Cl}_{2-\mathrm{x}} \mathrm{N}$ and anionic $\mathrm{CH}_{\mathrm{x}} \mathrm{Cl}_{2-\mathrm{x}} \mathrm{N}$ species are calculated, followed by the calculation of their gas-phase entropies. These combined calculations yield the free energy of gas phase radical $\mathrm{CH}_{\mathrm{x}} \mathrm{Cl}_{2-\mathrm{x}} \mathrm{N}$ and anionic $\mathrm{CH}_{\mathrm{x}} \mathrm{Cl}_{2-\mathrm{x}} \mathrm{N}$ species. The solvation energies of radical $\mathrm{CH}_{\mathrm{x}} \mathrm{Cl}_{2-\mathrm{x}} \mathrm{N}$ and anionic $\mathrm{CH}_{\mathrm{x}} \mathrm{Cl}_{2-\mathrm{x}} \mathrm{N}$ species are then calculated. The desired results of this work, reaction energies in both the gas phase and solution phase, can now be estimated, because the necessary thermodynamic quantities are known either from experiment, can be obtained from the previous study, or can be obtained from the calculations described herein.

For all species considered in this study the most favorable pathway was the one that resulted in a $\mathrm{Cl}^{-}$being expelled into solution. In addition, the results of this study suggest that a higher degree of chlorination correspond to a more favorable reduction. Relative to the non-substituted chlorinated methanes, the thermodynamic results suggest the $\mathrm{CH}_{\mathrm{x}} \mathrm{Cl}_{3-\mathrm{x}} \mathrm{F}, \mathrm{CH}_{\mathrm{x}} \mathrm{Cl}_{3-\mathrm{x}} \mathrm{OH}$, and $\mathrm{CH}_{\mathrm{x}} \mathrm{Cl}_{3^{-}}$ ${ }_{x}\left(\mathrm{HCO}_{3}\right)$ species are moderately more difficult to reduce, the $\mathrm{CH}_{\mathrm{x}} \mathrm{Cl}_{3-\mathrm{x}} \mathrm{SH}$ species is moderately less difficult to reduce, and the $\mathrm{CH}_{\mathrm{x}} \mathrm{Cl}_{3-\mathrm{x}}\left(\mathrm{NO}_{3}\right)$ species is substantially more favorable to reduce. The degradation of the nitrate substituted species gains substantial energy due to the fact that the radical $\mathrm{CH}_{\mathrm{x}} \mathrm{Cl}_{2-\mathrm{x}}\left(\mathrm{NO}_{3}\right)$ species readily decomposes into an aldehyde and $\mathrm{NO}_{2}$ gas. These results demonstrate that $a b$ initio electronic structure methods can be used to calculate the reaction energetics of a potentially large number of organic compounds with other aqueous species in natural waters and can be used to help identify the potentially important environmental degradation reactions.

\section{$\underline{\text { Parallel Projector Augmented-Wave Code }}$}

Iron oxides are important adsorbing surfaces for a large number of cations, anions, metal ions, and organic chelates in soils and other geologic materials. Because they are critical for determining the fate and transport of contaminants in natural systems, the adsorptive properties of iron oxides has been an area of intense geochemical research. While much about these surfaces has been learned from classical force field models, relatively little has been learned about these surfaces from first principles calculations due to their high computational costs. A new type of first-principles theory, Blöchl's PAW method, now offers an accurate and efficient way to treat iron-oxide surfaces. The PAW method is an all-electron approach that has many of the advantages of typical pseudopotential plane-wave (Car-Parrinello) approaches with the added ability to handle first-row elements with d electrons (Blöchl 1994). The PAW method is based on the density functional approximation to the full Schrödinger equation in which each allelectron Kohn-Sham molecular orbital is defined in terms of a smooth wave function (expanded in plane-waves) and a core part (expanded using a radial grid about each atom). This code will allow many new types of materials to be simulated at a first-principles level, including ironoxides. This code development will benefit the entire EMSL user community, and there are already plans to have the software developed on this project to be included in EMSL's NWChem program package. 
During FY 2001 several modifications were made to the PAW program. First it was modified to add load balancing. Before this modification, the load inbalance in the PAW program resulted in declining parallel performance at larger processor sizes (see Table B.1). New performance numbers are shown in Table B.2.

Table B.1. PAW Timings (parallel efficiencies) for $\mathrm{SO}_{3}+11 \mathrm{H}_{2} \mathrm{O}$ before load balancing modifications

\begin{tabular}{|c|l|l||}
\hline $\begin{array}{c}\text { Number of } \\
\text { Processors }\end{array}$ & $\begin{array}{c}\text { Cray-T3E } \\
\text { (seconds) }\end{array}$ & $\begin{array}{c}\text { IBM-SP } \\
\text { (Power2 160MHz) } \\
\text { (seconds) }\end{array}$ \\
\hline 6 & 64 & 51 \\
\hline 12 & $39(82 \%)$ & $25(102 \%)$ \\
\hline 24 & $21(76 \%)$ & $14(91 \%)$ \\
\hline 48 & $16(50 \%)$ & $10(64 \%)$ \\
\hline
\end{tabular}

Table B.2. PAW in seconds (parallel efficiencies) for $\left[\mathrm{Fe}\left(\mathrm{H}_{2} \mathrm{O}\right)_{6}\right]^{3+}$ cluster calculation. Determined from calculations on a linux cluster made up of dual processor $500 \mathrm{MHz}$ Pentium nodes connected via a Giganet high-speed network.

\begin{tabular}{|c|c|}
\hline $\begin{array}{c}\text { Number of } \\
\text { Processors }\end{array}$ & $\begin{array}{c}\text { Colony } \\
\text { (seconds) }\end{array}$ \\
\hline 8 & 143.13 \\
\hline 16 & $68.75(104 \%)$ \\
\hline 32 & $32.85(109 \%)$ \\
\hline 64 & $17.58(102 \%)$ \\
\hline
\end{tabular}

Second, a mulipole Ewald sum (i.e., not just s-component charges) was added to calculate solids. Results obtained for solids seem to be of good quality (e.g., lattice parameters for SiC: $a=4.41 \AA$ and $B=2.05$ Mbar). Finally, in FY 2001, free-space PAW and Gaussian DFT NWChem simulations were performed for a series of first-row transition metal monoxides and dioxides, $\mathrm{ScO}$, $\mathrm{TiO}, \mathrm{VO}, \mathrm{CrO}, \mathrm{MnO}, \mathrm{FeO}, \mathrm{TiO}_{2}, \mathrm{VO}_{2}, \mathrm{CrO}_{2}$, and $\mathrm{FeO}_{2}$ (Bylaska et al 2001). These small molecules, which are well characterized experimentally, are an extreme test of the reliability of an $a b$ initio method because they have a large number of low-lying states, many with high spin multiplicity. For the monoxides, the agreement in structural parameters was quite good between the two methods and with experiment (Table B.3). The worst-case difference was for the CrO molecule with absolute differences in distance, frequency, and binding energy being $0.015 \AA, 50 \mathrm{~cm}^{-1}$, and $0.37 \mathrm{eV}$ between the PAW/LDA/60Ry PAW and NWChem LDA/DZVP2 results. Again for the dioxides, the agreement between the two methods was also quite good (Table B.4). The worst-case difference was for the $\mathrm{TiO}_{2}$ molecule with absolute differences in distance, angle, frequency and atomization energy being $0.01 \AA, 1.1^{\circ}$, and $0.02 \mathrm{eV}$ between the PAW/LDA/60Ry PAW and NWChem/LDA/DZVP2 results. 
Table B.3. Structural parameters for first row transition metal monoxides

\begin{tabular}{||l|l|l|c|c|c||}
\hline \hline System(State) & \multicolumn{1}{|c|}{ Method } & $\mathbf{R}_{\mathbf{e}}(\mathbf{A})$ & $\omega_{\mathbf{e}}\left(\mathbf{c m}^{-1}\right)$ & $\omega_{\mathbf{e}} \chi_{\mathbf{e}}\left(\mathbf{c m}^{-1}\right)$ & $\mathbf{D}_{\mathbf{e}}(\mathbf{e V})$ \\
\hline${ }^{45} \mathrm{Sc}^{16} \mathrm{O}\left(\mathrm{X}^{2} \Sigma^{+}\right)$ & PAW/LDA/60Ry & 1.658 & 991 & 3.3 & 9.09 \\
\hline & NWChem/LDA/DZVP2 & 1.673 & 990 & 3.5 & 8.79 \\
\hline & Exp & 1.6682 & 964.95 & 4.2 & 7.02 \\
\hline${ }^{48} \mathrm{Ti}^{16} \mathrm{O}\left(\mathrm{X}^{3} \Delta_{\mathrm{r}}\right)$ & PAW/LDA/60Ry & 1.620 & 1020 & 3.6 & 9.03 \\
\hline & NWChem/LDA/DZVP2 & 1.615 & 1017 & 3.6 & 8.92 \\
\hline & Exp & 1.6202 & 1009.02 & 4.498 & 6.93 \\
\hline${ }^{51} \mathrm{~V}^{16} \mathrm{O}\left(\mathrm{X}^{4} \Sigma^{-}\right)$ & PAW/LDA/60Ry & 1.585 & 992 & 3.7 & 8.36 \\
\hline & NWChem/LDA/DZVP2 & 1.574 & 992 & 3.7 & 8.30 \\
\hline & Exp & 1.5893 & 1011.3 & 4.86 & 6.46 \\
\hline & PAW/LDA/60Ry & 1.585 & 960 & 5.0 & 5.68 \\
\hline & NWChem/LDA/DZVP2 & 1.600 & 910 & 4.2 & 6.05 \\
\hline & Exp & 1.615 & 898.4 & 6.7 & 4.46 \\
\hline & PAW/LDA/60Ry & 1.620 & 939 & 4.2 & 6.51 \\
\hline${ }^{55} \mathrm{Mn}^{16} \mathrm{O}\left(\mathrm{X}^{5} \Pi\right)\left(\mathrm{X}^{6} \Sigma\right)$ & NWChem/LDA/DZVP2 & 1.613 & 944 & 4.3 & 6.44 \\
\hline & Exp & 1.76 & 839.6 & 4.7 & 3.75 \\
\hline & PAW/LDA/60Ry & 1.599 & 935 & 4.1 & 6.65 \\
\hline${ }^{56} \mathrm{Fe}^{16} \mathrm{O}\left(\mathrm{X}^{5} \Delta\right)$ & NWChem/LDA/DZVP2 & 1.591 & 947 & 4.3 & 6.55 \\
\hline & Exp & 1.57 & 965 & -- & 4.26 \\
\hline
\end{tabular}

Table B.4. Structural parameters for first row transition metal dioxides

\begin{tabular}{|l|l|l|l|l||}
\hline \multicolumn{1}{|c|}{ System(State) } & \multicolumn{1}{|c|}{ Method } & \multicolumn{1}{|c|}{$\begin{array}{c}\text { R(MO) } \\
(\mathbf{A})\end{array}$} & $\begin{array}{c}\theta \text { (OMO) } \\
(\text { degrees) }\end{array}$ & \multicolumn{1}{c|}{$\begin{array}{c}\mathbf{D}_{\mathbf{e}} \\
(\mathbf{e V})\end{array}$} \\
\hline $\mathrm{TiO}_{2}\left({ }^{1} \mathrm{~A}_{1}\right)$ & PAW/LDA/60Ry & 1.653 & 110. & 1.71 \\
\hline & NWChem/LDA/DZVP2 & 1.643 & 108.9 & 1.69 \\
\hline $\mathrm{VO}_{2}\left({ }^{2} \mathrm{~A}_{1}\right)$ & PAW/LDA/60Ry & 1.613 & 109.3 & 1.59 \\
\hline & NWChem/LDA/DZVP2 & 1.602 & 108.3 & 1.57 \\
\hline $\mathrm{CrO}_{2}\left({ }^{3} \mathrm{~A}_{1}\right)$ & PAW/LDA/60Ry & 1.585 & 120.5 & 1.33 \\
\hline & NWChem/LDA/DZVP2 & 1.590 & 120.3 & 1.34 \\
\hline $\mathrm{FeO}_{2}\left({ }^{3} \mathrm{~A}_{1}\right)$ & PAW/LDA/60Ry & 1.572 & 132.1 & 1.30 \\
\hline & NWChem/LDA/DZVP2 & 1.569 & 132.3 & 1.27 \\
\hline
\end{tabular}

Study of the Bonding structure of 3D transition metal dimers with the Projector Augmented Plane Wave Method

An extensive study of the first-row transition metal dimers was completed using the newly developed massively parallel PAW program. In this work, the results were compared with similar calculations performed using local basis set methods (NWChem), and the general trends and properties of the bonding structure of $3 \mathrm{~d}$ transition metal dimmers were discussed. The properties of transition metal dimers are primarily determined by the interaction between $3 \mathrm{~d}$ and $4 \mathrm{~s}$ valence states. The spatial character of the two states is very different- $3 \mathrm{~d}$ orbitals are 
localized around the nucleus, whereas $4 \mathrm{~s}$ orbitals are much more diffuse. As a result, there is a competition between short-range $3 \mathrm{~d}$ bonding and long range $4 \mathrm{~s}$ bonding. Population analysis from PAW and NWChem calculations also shows a strong interaction between $3 \mathrm{~d}$ and $4 \mathrm{p}$ orbitals. The presence of valence $3 \mathrm{~d}$ states is also responsible for the fact there is many low lying states in transition metal dimers. All these factors make these systems a fairly hard test for any computational approach.

A variety of spin states can be observed among the ground-state configurations of first-row transition metal dimers. Both PAW and NWChem predict the same ground-state multiplicities, and the agreement between bond lengths and bond energies is also very good. Some basic trends are that both spin multiplicities decrease as one goes from $\mathrm{Sc}_{2}$ to $\mathrm{Cr}_{2}$. The filling of the bonding orbitals (see Figure B.5) nicely explains these trends. Starting with $\mathrm{Mn}_{2}$, the antibonding orbitals are being filled, and as expected, there is a slight increase of the bond lengths. The trends in the spin multiplicities are less obvious in the latter dimers, which are characterized by very high magnetic moments.
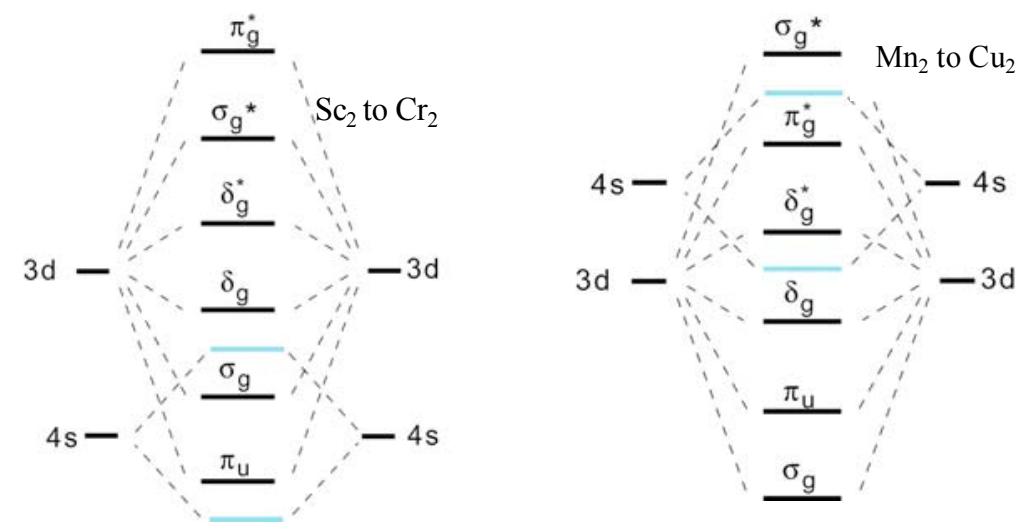

Figure B.5. Orbital correlation diagrams for the first-row transition metal dimers. The change in correlation diagrams is essentially a result of the 4 s atomic orbital moving up as the atomic number increases. This moving up is caused by the $3 \mathrm{~d}$ orbitals screening the nuclear charge. The interaction with the $4 p$ orbitals (not shown) in some cases causes the $\pi$ orbital to be below the $\sigma$ orbital.

\section{References}

Blöchl, PE, O Jepsen, and OK Andersen. 1994. "Improved Tetrahedron Method for Brillouinzone Integrations." Phys., 49(23):16223-16233, Rev. B.

Chmelnik, AM and DN Fiat. 1972. "Hydration of the Vanadium (III) Ion by Oxygen-17 and Proton Magnetic Resonance”. J. Magn. Reson., 8:325-331.

Herdman, GJ and PS Salmon. 1991. "Dynamics of Water Protons in Concentrated GA3+, AL3+, FE3+ and DY3+ Aqueous-Solutions - A Study Using Incoherent Quasi-Elastic NeutronScattering." J. Am. Chem. Soc., 113:2930-2939. 
Herdman, GJ and GW Neilson. 1990. "Neutron Scattering Studies of Aqua Ions." J. Molecular Liquids, 46:165.

Lubin, MI, EJ Bylaska, and JH Weare. 2000. "Ab Initio Molecular Dynamics Simulations of Aluminum Ion Solvation in Water Clusters." Chem. Phys. Lett., 322:447-453.

Pasquarello, A, I Petri, PS Salmon, O Parsiel, R Car, E Toth, DH Powell, HE Fisher, L Heim,

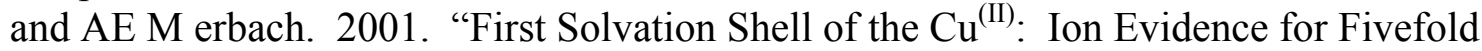
Coordination." Science, 291(5505):856-859.

Salmon, PS, and PB Lond. 1992. "The Structure of CL" Solutions in Etehylene-Glycol Studied by Neutron-Diffraction.” J. Phys. C., 4(23):5249-5262.

Salmon, PS, MC Bellissent-Funel, and GJ Herdman. 1990. "Condensed Matter." J. of Phys., 2:4297.

Salmon, PS, GJ Herdman, and J Lindgren. 1989. “Condensed Matter.” J. of Phys., 1:3459.

Salmon, PS. 1987. "The Dynamics of Water Molecules in Ionic Solution: I. The Application Of Quasi-Elastic Neutron Scattering to the Study of Translational Diffusive Proton Motion." J. of Phys. C., 20:1573.

Sjoberg, S, L Ohman, and N Ingri. 1985. "Equilibrium and Structural Studies of Silicon(IV) and Aluminium(III) in Aqueous Solution. 11. Polysilicate Formation in Alkaline Aqueous Solution. A Combined Potentiometric and 29Si NMR Study." Acta Chemica Scand., 39:93-107.

Svensson, I, S Sjoberg, and L Ohman. 1986. "Polysilicate Equilibria in Concentrated SodiumSilicate Solutions.” J. Chem. Soc. Faraday Trans., 1(82):3635-3646. 


\section{Appendix C - Full Report of Third Year Activities and Accomplishments}

\section{Simulations of the Rough P. aeruginosa LPS Membrane - Goethite Mineral}

Molecular simulations of the membrane interacting with the mineral have been carried out, based on the molecular models developed in this project for the LPS membrane and the goethite mineral fragment. Using these models, MD simulations were performed at room temperature and pressure of the membrane in close proximity to a mineral fragment. A snapshot of the simulated system is shown in Figure C.1. Over a nanosecond of simulation, trajectories have been collected and analyzed for a range of properties. These simulations were carried out to provide insight into the importance of the intrinsic flexibility of the polysaccharide component of the LPS membrane for adsorption to mineral surfaces. One of the key question that this study was designed to address is, "How does the LPS membrane attach to mineral surfaces?" From the simulations the LPS functional groups that are specifically involved in interactions with a mineral surface have been determined.

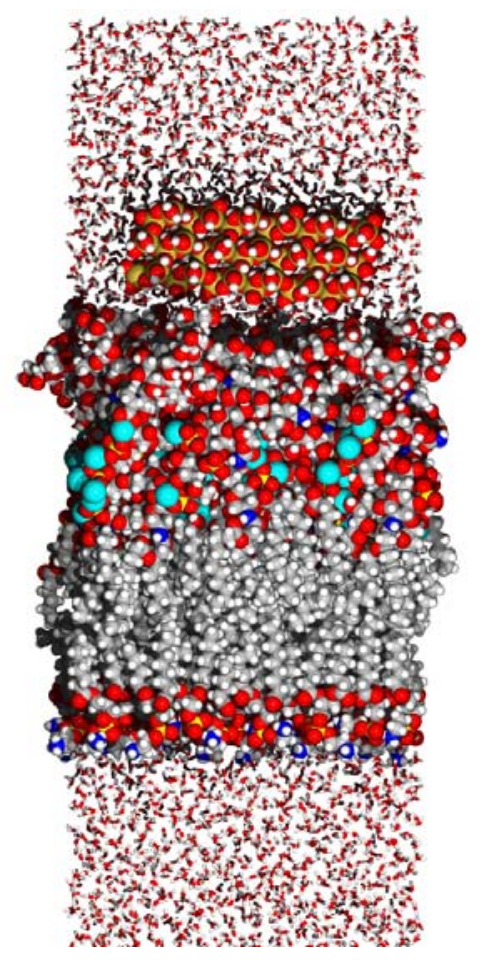

Figure C.1. Molecular representation of the LPS membrane of $P$. aeruginosa in near contact with the goethite mineral fragment.

The structural reorientation of the membrane was determined using vectors that define the orientation of the saccharide as follows. The vectors point from the center of geometry of the atoms $\mathrm{OR}, \mathrm{C} 1$, and $\mathrm{C} 2$ to the center of geometry of the atoms $\mathrm{C} 3, \mathrm{C} 4$ and $\mathrm{C} 5$, using the common numbering of pyranose rings. This definition is identical to the one used in the project team's analysis of the average motion of saccharide groups in the membrane. The angle between this orientation vector and the $z$-axis is $\theta$, with $0^{\circ}<\theta<180^{\circ}$. The vector $z$-projection points away from the surface for $\theta=180^{\circ}$, and toward the surface for $\theta=0^{\circ}$. The angle between the $x y$-projection 
and the $y$-axis is $\varphi$, with $0^{\circ}<\varphi<360^{\circ}$. The $x y$-projection points in the negative $y$-direction for $\varphi=0^{\circ}$, in the $x$-direction for $\varphi=90^{\circ}$, in the $y$-direction for $\varphi=180^{\circ}$, and in the negative $x$-direction for $\varphi=270^{\circ}$. The probability that the vector has a given orientation of $\theta$ and $\varphi$ is given by $\mathrm{P}(\theta, \varphi)=\mathrm{P}(\theta) \mathrm{P}(\varphi)$, where $\mathrm{P}(\theta)$ and $\mathrm{P}(\varphi)$ are the probabilities that the vector has an orientation with the specified angles. Simulations of the membrane, the mineral, and the combined system have been analyzed for structural differences in hydration and hydrogen bonding patterns from radial distribution functions, and for specific mineral-membrane interactions and mineral-induced conformational changes in the saccharide region of the membrane using the orientational vectors. Comparison of simulation reveals a significant perturbation of the saccharide groups as a result of the presence of the mineral. Orientational vectors still favor being directed towards the inner core $\left(\theta=0^{\circ}\right)$. The anisotropy with respect to vector precession about the $z$-axis, however, has changed significantly. Larger peak heights for the mineral-membrane system indicate restrained motion of these saccharide groups relative to the isolated membrane. This is to be expected because of hydrogen bonding between the mineral and membrane. Analysis of all 16 LPS units, in both the isolated membrane and the mineral-membrane systems, was performed, and the LPS units with the largest changes in saccharide group orientation were determined. Tall peaks with narrow bases indicate only a modest degree of saccharide motion and a comparison of saccharide peaks from the inner core region to those of the outer core indicates greater motion in the outer core. Since the motion of the saccharide groups is limited in the time scale of nanoseconds, comparison vector angle distributions provides a good estimate of the perturbation of the mineral on the membrane. The saccharide groups with only small changes in their average orientations are NAG1, NAG2, KDO1, KDO2, HEP1, HEP2, RHA, and GLC2. They are located inside the membrane and do not come into direct contact with the mineral. There are significant changes in orientation of the GLC*, GLC1, and GLC3 saccharide groups, which are located near or at the surface of the membrane. Of these three groups, inspection of multiple snapshots shows that the GLC3 saccharide of this LPS unit forms hydrogen bonds to the 110 mineral surface. The other saccharide groups of the LPS did not form hydrogen bonds with the surface and their orientational changes are smaller in magnitude.

\section{$\underline{\text { Pressure-Induced Hydrogen Trapping in Water Clusters }}$}

The solvation of the electron in water clusters has attracted a constant interest from both the theoretical and experimental point of view. While the localization of the excess electron in bulk water was experimentally discovered long ago, and there is a good understanding of the properties of the solvated state, many questions are unanswered regarding the process of electron solvation in finite water clusters. Several ab initio numerical simulations on $\left(\mathrm{H}_{2} \mathrm{O}\right)_{\mathrm{n}}$, with $\mathrm{n}$ in the range 1 to 12 have been reported in the literature. The large amount of computer time required for full quantum mechanical calculations made the approach of bigger systems, even with today's supercomputers, impossible. Alternative treatments based on mixed models (use of pseudopotentials for water molecules) have been developed, but the disagreement with experiments made their predictive strength less powerful. The difficulty of a direct computational approach to large water clusters has been related to the accuracy requirements for a correct description of the hydrogen bonding. These requirements led to an increase in the computer time that is still beyond reach. 
Since simulations of electron solvation in large water clusters is still a computationally challenging problem, the project team has been searching for alternatives that would result in a better insight into the role played by different Hamiltonian components in the geometrical and electronic structure of the equilibrium state. Alternative simulation strategies need to create a more balanced competition between hydrogen bonding, chemical bonding inside water molecules, and the interaction between the water dipoles and solvated electron. One such strategy is to confine water clusters by an external potential or a canonical pressure. Such a simulation strategy is in the spirit of dynamical simulation of periodic systems under constant pressure (Parrinello 1982; Focher et al. 1994; Scandolo et al. 1995; Serra et al. 1998; Cavazzoni et al. 1998), and a recent extension to finite systems (Martonak et al. 2000).

The project team has been developing and using a different approach to creating a pressured-like environment for the quantum MD simulation in finite $\left(\mathrm{H}_{2} \mathrm{O}\right)_{n}{ }_{n}^{-}$clusters. Namely, an external confining potential that is coupled to the ionic subsystem is being used. The strength of the potential is small enough as to not overwhelm the bonding of the system. Therefore, it should be a useful method for looking for alternative $\left(\mathrm{H}_{2} \mathrm{O}\right)_{\mathrm{n}}{ }^{-}$structures. To assess the power of the method, the method was applied to an $a b$ initio MD study of an anionic $\left(\mathrm{H}_{2} \mathrm{O}\right)_{12}{ }^{-}$cluster. Ultimately, a chemical reaction was observed in which an ionic hydrogen molecule emerges and gets trapped inside a cage-like structure formed from the oxygen and the remaining hydrogen ions (Figure C.2).

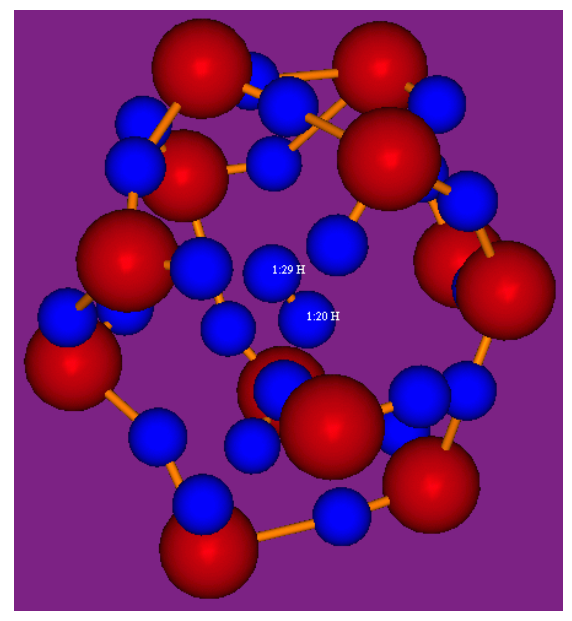

Figure C.2. Optimized structure for the $\left(\mathrm{H}_{2} \mathrm{O}\right)_{12}{ }^{-}$cluster found using the confining potential technique.

Important information about the forces that maintain the stability of the structure can be inferred from the analysis of the distribution of charge in the cluster. The project team calculated the total charge inside spheres of different radii around the mass center of the central $\mathrm{H}_{2}$ molecule. The results show that the $\mathrm{H}_{2}$ molecule binds a total charge of 1e-. For example, the charge enclosed in a sphere of radius $0.7 \AA$ is $1.06 \mathrm{e}^{-}$. This finding is consistent with a picture in which the central molecule contains a single electron and therefore forms an $\mathrm{H}_{2}{ }^{+}$ion. The natural conclusion then is that the role of the two protons removed from the solvation shell is to create a deeper quantum well inside the cage and, in this way, to compensate the increase in the kinetic energy of the excess electron due to the confinement in a smaller space volume. By the removal 
of the two protons two negative ions, an $\mathrm{OH}^{-}$and an $\mathrm{O}_{2} \mathrm{H}_{3}{ }^{-}$, are left on the solvation shell. These two ionic species have been the subject of intense research lately in the literature (Tuckerman et al. 1997). Subsequently, they are electrostatically integrated in the rest of the solvation shell. The shape of the cluster can then be understood as the result of the interaction between the net positive charge of the central molecule and the net charge of two electrons localized on the cage.

Development Of A Parallel Three-Dimensional Fast Fourier Transform Based On a Hilbert Space Filling Curve

Many groups have shown that plane-wave programs can be made parallel relatively easily, and several parallel implementations of plane-wave programs have shown excellent scaling to a large number of processors (Bylaska et al. 1992; Haynes 2000; Marx 2000; Nelson 1993; Wiggs 1994). There are several ways to parallelize a plane-wave program. For many solid-state calculations, the computation can be distributed over the Brillouin zone sampling space. However, this approach is limited by the size of the Brillouin zone sampling space, which is usually very small. Another approach is to distribute the one-electron orbitals across processors. This approach has been shown to scale quite well. Unfortunately, this method will not work for jobs with large cutoff energy requirements (i.e., using large numbers of plane-waves to describe the one-electron orbitals) on parallel computers that have nodes with a small amount of memory, because a complete one-electron orbital must be stored on each node. Finally, another straightforward way is to do a spatial decomposition of the one-electron orbitals. This approach is the most versatile, and easily implemented. However, a parallel three-dimensional fast Fourier transform (FFT) must be used.

Both plane-wave modules (i.e., PSPW and Band) implemented in NWChem are parallelized using a spatial decomposition approach (i.e., distributing the plane-wave basis set across tasks). The required parallel FFT was implemented using a slab decomposition of the three-dimensional FFT block as shown in Figure C.3. This parallel FFT is built from one-dimensional FFTs and a parallel matrix transpose. The program package FFTPACK is used to perform the one-dimensional FFTs. In Table C.1, the overall performance of the development projector augmented plane-wave (PAW) program is shown. The performance of the program is quite good with an overall parallel

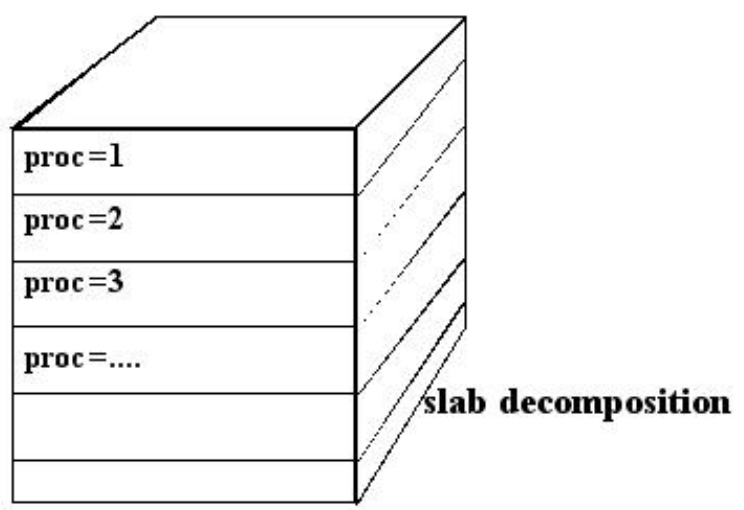

Figure C.3. Slab decomposition of the three-dimensional FFT efficiency to 64 processors being perfect. However, not every part the program scales perfectly. For illustrative purposes, the total electronic update step time was divided into four parts: 1) t1 being dominated by FFT calculations, 2) $\mathrm{t} 2$ being dominated by Lagrange multiplier or orthonormality calculations, 3 ) $\mathrm{t} 3$ being the time elapsed generating exchange-correlation matrix elements for the one-center atomic contributions in the PAW algorithm (Blochl 1994; Bylaska et al. 2002; Valiev 1999), and 4) t4 being dominated by applying the projector functions. 
Table C.1. Timings in seconds (parallel efficiencies) for a PAW $\left[\mathrm{Fe}\left(\mathrm{H}_{2} \mathrm{O}\right)_{6}\right]^{3+}$ cluster calculation. Determined from calculations on a Linux cluster made up of dual processor $500 \mathrm{MHz}$ Pentium nodes connected via a Giganet high-speed network.

\begin{tabular}{|c|c|c|c|c|c||}
\hline $\begin{array}{c}\text { Number } \\
\text { of Tasks }\end{array}$ & $\begin{array}{c}\text { Total Electronic } \\
\text { Update Step }\end{array}$ & $\mathbf{t 1}$ & \multicolumn{1}{|c|}{$\mathbf{t 2}$} & \multicolumn{1}{|c|}{$\mathbf{t 3}$} & \multicolumn{1}{|c|}{$\mathbf{t 4}$} \\
\hline 8 & 143.14 & 10.31 & 23.97 & 86.31 & 22.55 \\
\hline 16 & $68.75(104 \%)$ & $7.21(71 \%)$ & $11.60(103 \%)$ & $38.14(113 \%)$ & $11.80(95 \%)$ \\
\hline 32 & $32.85(109 \%)$ & $2.75(94 \%)$ & $5.57(108 \%)$ & $18.74(115 \%)$ & $5.79(97 \%)$ \\
\hline 64 & $17.58(102 \%)$ & $2.35(55 \%)$ & $2.55(118 \%)$ & $9.83(110 \%)$ & $2.85(99 \%)$ \\
\hline
\end{tabular}

The efficiency of part t1 shows that the parts of the program with the worst efficiency are FFTs. However, these inefficiencies are damped out due to the fact that the FFT part of the code makes up less than $10 \%$ of the overall computation.

A limitation of this parallelization strategy is that the FFT block is divided along the third dimension, or slab decomposed. A consequence of this is that you cannot use more processors than the size of the third dimension (e.g., a $64 \times 64 \times 64$ FFT block can use at most 64 processors). In terms of the parallel performance of just the parallel three-dimensional FFT on distributed memory parallel machines, this is not much of a limitation, because in performing a parallel three-dimensional FFT, the data communicated is on the same order as the number of floating point operations. Even though it is difficult to get parallel performance for parallel FFTs beyond that of slab decomposed FFTs, using finer scaled decompositions can still be of utility in a planewave program since the other parts of the plane-wave program are expected to scale to quite a large number of tasks. For example, if we use the performance numbers reported in Table C.1, then we can estimate the parallel efficiencies to be $90 \%$ for 128 tasks, $73 \%$ for 256 tasks, and $53 \%$ for 512 tasks. These estimated parallel efficiencies are based on the assumptions that the time spent in the FFT routines remains constant and the time spent in the other routines scales perfectly.

A massively parallel plane-wave program will be more straightforward to develop if the spatial decomposition used by the parallel FFT is used to represent real-space and reciprocal-space. However, using a finer-scaled decomposed parallel FFT instead of a slab-decomposed FFT will only be viable if its performance is at least as good as the slab-decomposed FFT. In Table C.2, timings are reported for a complex-to-complex FFT spatially decomposed along the second and third dimension, and for a slab-decomposed, complex-to-complex FFT. To generate the twodimensional spatial decomposition, the tasks were block mapped to a two-dimensional Hilbert curve spanning the grid of the second and third dimensions (see Figure C.4). The twodimensional Hilbert parallel FFT was built from one-dimensional FFTs and a parallel block rotation, and the program package FFTPACK was used to perform the one-dimensional FFTs. The Hilbert decomposition reduces the latency of the parallel block rotation to be proportional to the square root of the number of tasks used. Table C.2 shows the timings of the two different parallel FFTs are about the same. Unfortunately, no improvements are seen in using a large number of tasks with the two-dimensional Hilbert parallel FFT. However, the timings do not become worse. Consequently, using a two-dimensional Hilbert parallel FFT is a viable strategy for a massively parallel implementation of the plane-wave program. 

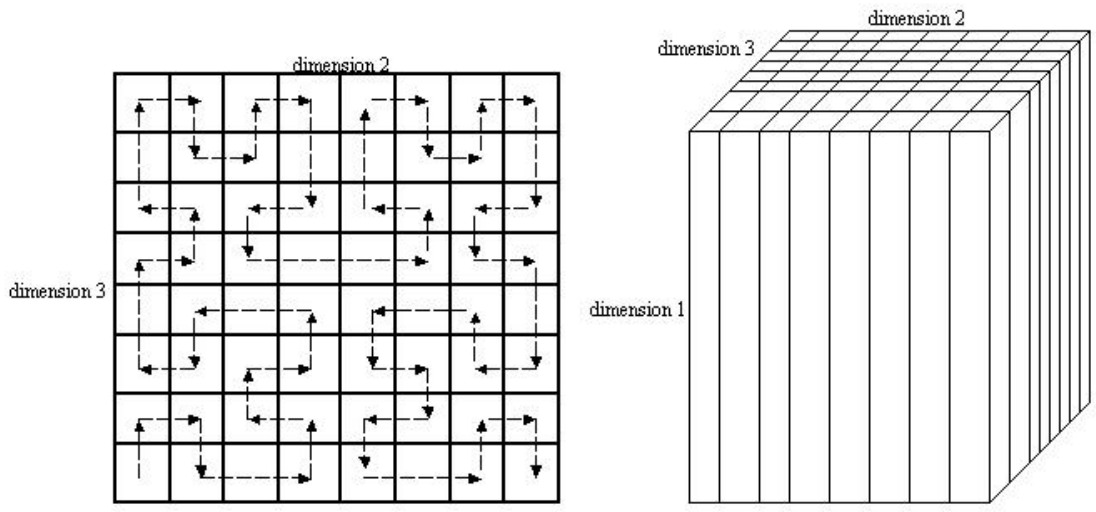

Figure C.4. The two-dimension Hilbert decomposition of the three-dimensional FFT grid.

Table C.2. Timings in seconds for complex-to-complex, three-dimensional FFTs. Determined from calculations on a Linux cluster made up of dual-processor, 500-MHz Pentium nodes connected via a Giganet high-speed network.

\begin{tabular}{|c|c|c|c|c|c|c|c|}
\hline Grid Size & $\begin{array}{l}\text { Number } \\
\text { of Tasks }\end{array}$ & Hilbert & Slab & Grid Size & $\begin{array}{l}\text { Number } \\
\text { of Tasks }\end{array}$ & Hilbert & Slab \\
\hline $16 \times 16 \times 16$ & 1 & $7.44 \mathrm{E}-03$ & $8.57 \mathrm{E}-03$ & $64 \times 64 \times 64$ & 1 & $9.10 \mathrm{E}-01$ & $9.51 \mathrm{E}-01$ \\
\hline \multirow[t]{11}{*}{ (10000 steps) } & 2 & $8.08 \mathrm{E}-03$ & $4.43 \mathrm{E}-02$ & (100 steps) & 2 & $6.71 \mathrm{E}-01$ & $5.90 \mathrm{E}-01$ \\
\hline & 4 & $6.25 \mathrm{E}-03$ & $2.25 \mathrm{E}-02$ & & 4 & $3.37 \mathrm{E}-01$ & $3.17 \mathrm{E}-01$ \\
\hline & 8 & $3.31 \mathrm{E}-03$ & $1.21 \mathrm{E}-02$ & & 8 & $1.97 \mathrm{E}-01$ & $1.66 \mathrm{E}-01$ \\
\hline & 16 & $2.61 \mathrm{E}-03$ & $7.55 \mathrm{E}-03$ & & 16 & $1.01 \mathrm{E}-01$ & $1.03 \mathrm{E}-01$ \\
\hline & 32 & $2.95 \mathrm{E}-03$ & -------- & & 32 & $7.16 \mathrm{E}-02$ & $4.10 \mathrm{E}-02$ \\
\hline & 64 & $3.04 \mathrm{E}-03$ & $\begin{array}{l}------- \\
\end{array}$ & & 64 & $5.48 \mathrm{E}-02$ & $2.52 \mathrm{E}-02$ \\
\hline & 80 & $3.20 \mathrm{E}-03$ & $\begin{array}{l}------ \\
\end{array}$ & & 80 & 4.98E-02 & -------- \\
\hline & 96 & $5.29 \mathrm{E}-03$ & -------- & & 96 & $3.78 \mathrm{E}-02$ & ------- \\
\hline & 128 & $4.84 \mathrm{E}-03$ & ------- & & 128 & $1.49 \mathrm{E}-02$ & ------- \\
\hline & 144 & $4.77 \mathrm{E}-03$ & ------- & & 144 & $1.78 \mathrm{E}-02$ & ------- \\
\hline & 160 & $5.27 \mathrm{E}-03$ & $\begin{array}{l}------ \\
--1\end{array}$ & & 160 & $1.84 \mathrm{E}-02$ & $\begin{array}{l}------ \\
--1\end{array}$ \\
\hline $32 \times 32 \times 32$ & 1 & $1.07 \mathrm{E}-01$ & $1.06 \mathrm{E}-01$ & $\begin{array}{l}128 \times 128 \times 1 \\
28\end{array}$ & 1 & $7.44 \mathrm{E}+00$ & $7.98 \mathrm{E}+00$ \\
\hline \multirow[t]{11}{*}{ (1000 steps) } & 2 & $7.33 \mathrm{E}-02$ & $6.35 \mathrm{E}-02$ & (20 steps) & 2 & $5.46 \mathrm{E}+00$ & $5.48 \mathrm{E}+00$ \\
\hline & 4 & $3.74 \mathrm{E}-02$ & $3.32 \mathrm{E}-02$ & & 4 & $2.74 \mathrm{E}+00$ & $2.64 \mathrm{E}+00$ \\
\hline & 8 & $2.51 \mathrm{E}-02$ & $2.45 \mathrm{E}-02$ & & 8 & $1.65 \mathrm{E}+00$ & $1.39 \mathrm{E}+00$ \\
\hline & 16 & $2.04 \mathrm{E}-02$ & $6.24 \mathrm{E}-02$ & & 16 & $8.66 \mathrm{E}-01$ & $7.45 \mathrm{E}-01$ \\
\hline & 32 & 7.74E-03 & $3.41 \mathrm{E}-02$ & & 32 & $5.87 \mathrm{E}-01$ & $4.16 \mathrm{E}-01$ \\
\hline & 64 & $5.24 \mathrm{E}-03$ & -------- & & 64 & $3.02 \mathrm{E}-01$ & $2.35 \mathrm{E}-01$ \\
\hline & 80 & $7.11 \mathrm{E}-03$ & -------- & & 128 & $1.62 \mathrm{E}-01$ & $9.86 \mathrm{E}-02$ \\
\hline & 96 & $7.40 \mathrm{E}-03$ & -------- & & 144 & $2.37 \mathrm{E}-01$ & -------- \\
\hline & 128 & 5.99E-03 & -------- & & 160 & $2.85 \mathrm{E}-01$ & -------- \\
\hline & 144 & $5.85 \mathrm{E}-03$ & -------- & & & & \\
\hline & 160 & $8.25 \mathrm{E}-03$ & -------- & & & & \\
\hline
\end{tabular}




\section{$\underline{\text { References }}$}

Blochl, PE. 1994. "Projector Augmented-Wave Method.” Phys. Rev. B, 50:17953-17979.

Bylaska, EJ, M Valiev, R Kawai, and JH Weare. 2002. "Parallel Implementation of the Projector Augmented Plane Wave Method for Charged Systems.” Comput. Phys. Comm., 143:11-28.

Cavazzoni, C, GL Chiarotti, S Scandolo, E Tosatti, M Bernasconi, and M Parrinello. 1999. "Superionic and Metallic States of Water and Ammonia at Giant Planet Conditions." Science, 283:44.

Clarke, LJ, I Stich, and MC Payne. 1992. "Large-Scale Ab Initio Total Energy Calculations on Parallel Computers." Comput. Phys. Comm., 72:14-28.

Focher, P, GL Chiarotti, M Bernasconi, E Tosatti, and M Parrinelo. "Structural PhaseTransformations via $1^{\text {st }}$-Principles Simulation.” 1994. Europhys. Lett., 26:345.

Haynes, PD and M Cote. 2000. "Parallel Fast Fourier Transforms for Electronic Structure Calculations.” Comput. Phys. Comm., 130:130-136.

Marx, D and J Hutter. 2000. "Ab Initio Molecular Dynamics: Theory and Implementation." In Modern Methods and Algorithms of Quantum Chemistry; Grotendorst. J., Ed.;

Forschungszentrum, Vol. 1; pp. 301-449: Julich, Germany.

Martonak, R, C Molteni, and M Parrinello. 2000. Ab Initio Molecular Dynamics with a Classical Pressure Reservoir: Simulation of Pressure-Induced Amorphization in a $\mathrm{Si}_{35} \mathrm{H}_{36}$ Cluster." Phys. Rev. Lett., 84:682.

Nelson, JS, SJ Plimpton, and MP Sears. 1993. "Plane-Wave Electronic-Structure Calculations on a Parallel Supercomputer." Phys. Rev., B, 47:1765.

Parrinello, M, and A Rahman. 1982. "Strain Fluctuations and Elastic Constants." J. Chem. Phys., 76:2662.

Scandolo, S, M Bernasconi, GL Chiarotti, P Focher, and E Tosatti. 1995. "Pressure-Induced Transformation Path of Graphite to Diamond." Phys. Rev. Lett., 74(20):4015-4018.

Serra, S. 1998. "Pressure-Induced Magnetic Collapse and Metallization of Molecular Oxygen: The zeta- $\mathrm{O}_{2}$ Phase." Phys. Rev. Lett., 80:5160-5163.

Tuckeraman, ME, D Marx, ML Klein, and M Parrinello. 1997. "On the Quantum Nature of the Shared Proton in Hydrogen Bonds." Science, 275:817-820.

Valiev, M, and JH Weare. 1999. "The Projector-Augmented Plane Wave Method Applied to Molecular Bonding." J. Phys. Chem. A, 103:10588-10601. 
Wiggs, J, and H Jonsson. "Parallel Implementation of the Car-Parrinello Method by Orbital Decompositions.” 1994. Comput. Phys. Comm., 81:1. 